\title{
Phase Change Material Blind System for Double Skin Façade Integration: System Development and Thermal Performance Evaluation
}

\author{
Yilin Li ${ }^{a}, *$ Jo Darkwa ${ }^{\mathrm{b}}$, Georgios Kokogiannakis ${ }^{\mathrm{c}}$, Weiguang $\mathrm{Su}^{\mathrm{d}}$ \\ aSchool of Environment and Architecture, University of Shanghai for Science and \\ Technology, 516 Jungong Road, Shanghai 200093, China \\ ${ }^{b}$ Faculty of Engineering, University of Nottingham, University Park, Nottingham, \\ NG7 2RD, UK \\ 'Sustainable Buildings Research Centre (SBRC), University of Wollongong, \\ Australia, Innovation Campus, Fairy Meadow, NSW 2519, Australia \\ ${ }^{\mathrm{d}}$ School of Mechanical \& Automotive Engineering, Qilu University of Technology \\ (Shandong Academy of Sciences), Jinan 250353, China \\ *Corresponding author: Yilin Li \\ E-mail address: yilin.li@usst.edu.cn
}

\begin{abstract}
Double skin facades (DSFs) are often applied as energy reducing elements in modern buildings, but do experience overheating problems in warm seasons which may contribute to increase in cooling loads. There are currently various thermal management devices being used in DSF but have limitations such as secondary thermal transmittance and low energy storage capacity. In this paper, a novel laminated composite phase change material (PCM) blind system with high thermal energy storage capacity has been developed and evaluated in a typical DSF building. The results showed that the integrated PCM blind system was able to keep the average air temperature in the DSF below $35^{\circ} \mathrm{C}$ during the monitored period in summer and showed no significant increase as compared with the ambient temperature. The surface temperature of the inner skin of the DSF was also reduced up to about $2.9^{\circ} \mathrm{C}$ as compared with the external skin surface temperature thus reducing heat transfer into the building. By using validated numerical models, the PCM blind was found to perform thermally better than a conventional aluminium blind. Finally, design and operational parameters of the PCM
\end{abstract}


blind including the blind tilt angle and its position were optimised. Further comparative studies against other integrated DSF systems are however being encouraged to establish the full effectiveness of the developed PCM blind system.

Keywords: Double skin façade; PCM; System development; Thermal performance evaluation

\begin{tabular}{|ll|}
\hline Nomenclature \\
$C_{p}$ & specific heat $(\mathrm{kJ} / \mathrm{kg} \cdot \mathrm{K})$ \\
$Q$ & heat $(\mathrm{W})$ \\
$H$ & enthalpy $(\mathrm{kJ} / \mathrm{kg})$ \\
$\Delta H$ & latent heat $(\mathrm{kJ} / \mathrm{kg})$ \\
$I$ & radiation intensity \\
$T$ & temperature $(\mathrm{K})$ \\
$\Delta T$ & temperature difference $(\mathrm{K})$ \\
$S_{\varphi}$ & user-defined source term \\
$\Omega$ & solid angle $\left({ }^{\circ}\right)$ \\
$\phi$ & phase function \\
$\varphi$ & a common variable that refers \\
& to the continuity equation, \\
& temperature, and velocity \\
$a$ & absorption coefficient (m ${ }^{2}$ \\
& /mol) \\
$h$ & convective heat transfer \\
& coefficient $\left(\mathrm{W} / \mathrm{m}^{2} \mathrm{~K}\right) / \mathrm{sensible}$ \\
& enthalpy (kJ/kg) \\
$k$, & thermal conductivity (W/mK) \\
$n$ & refractive index \\
$s$ & path length (m) \\
$\vec{S}$ & position vector \\
$\vec{S}$ & direction vector \\
$\vec{S}$, & scattering direction vector \\
$t$ & time (s) \\
\hline &
\end{tabular}

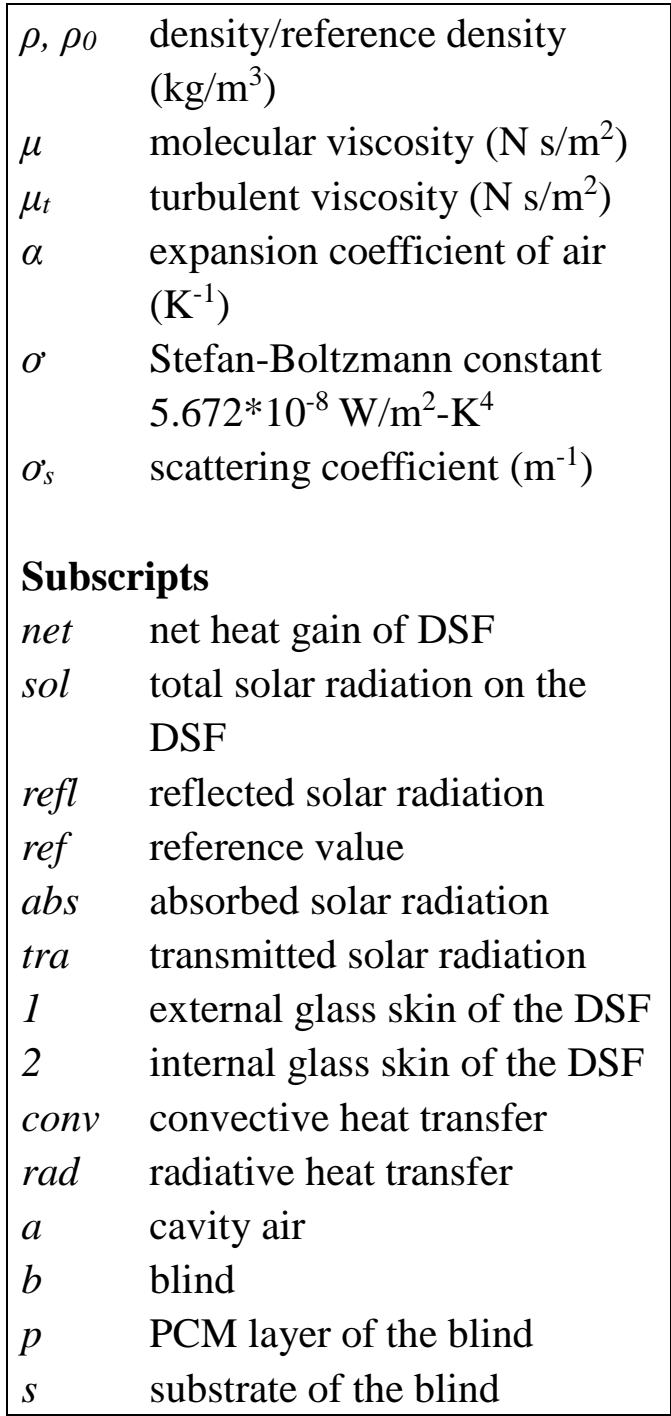




\section{Introduction}

\subsection{Background and related studies}

The building sector has been identified as one of the main contributors of global energy consumption representing over $40 \%$ of the end-use energy in the world [1]. This large amount of energy consumption has resulted in a global trend of green buildings designs which include integrations of low carbon technologies and building facades $[2,3]$. During the last decades, architects and researchers have promoted many sustainable façade designs to reduce the energy consumption in buildings without sacrificing the aesthetic and lighting benefits of glazed facades. Amongst them double skin façades have been widely applied to buildings due to their great benefits such as adding extra thermal insulation, bringing natural daylighting, and provision of natural ventilation without mechanical devices and extra energy consumption [4].

A double skin facade (DSF) is normally described as building envelope consisting of an external wall (outer skin), an internal wall (inner skin), and an air cavity between the two skins [5]. Shading devices may be applied to double skin facades in order to avoid the glare and overheating problems. Past studies have shown that DSFs are capable of reducing energy consumption under different climatic regions around the world. For instance, Pasquay [6] monitored a high-rise DSF building in Germany and found the DSF achieve about $15 \%-18 \%$ savings in heating energy during winter period as well as help to maintain indoor temperature below $30^{\circ} \mathrm{C}$ during the summer season. Kim et al. $[7,8]$ conducted both experimental and simulation studies on a DSF building located in South Korea. They found out that the DSF could provide adequate natural ventilation with preheated supply air through the cavity and also reduce the heating load by about $18.7 \%$ in winter periods. In subtropical areas such as Hong Kong, Chan et al. [9] demonstrated that a DSF system with double reflective glazing as external skin was capable of saving around $26 \%$ of energy consumption in buildings. The above results highlight some of the energy saving potentials of DSFs in buildings.

However, DSFs could sometimes experience overheating problems especially in warm The short version of the paper was presented at ICAE2018, Aug 22-25, Hong Kong. This paper is a substantial extension of the short version of the conference paper. 
seasons which weakens its energy saving capacity. For instance, Pasquay [6] observed some level of overheating in the DSF cavity with occasional air temperature exceeding $40^{\circ} \mathrm{C}$. Saelens [10] conducted both numerical and experimental studies and found the inlet temperature of a naturally ventilated DSF was more than $35^{\circ} \mathrm{C}$ on a summer day in Belgium. Tanimoto [11] simulated the temperature distribution of a double skin air flow window and found the simulated cavity air temperature to be around $38^{\circ} \mathrm{C}$ against outdoor temperature of $34^{\circ} \mathrm{C}$. In our previous work, an outlet temperature of about $41^{\circ} \mathrm{C}$ was obtained from a multi-storey DSF building located in a hot-summer and coldwinter region in China [12]. These overheating problems in DSFs may directly affect the indoor thermal comfort, increase the cooling load in warm seasons, and eventually result in increase of energy consumption in buildings.

To overcome the overheating issues affecting double skin facades, different solutions have been investigated including physical design considerations of DSFs and flexible integrated thermal management devices. There are mainly three design considerations: (1) ensuring proper distance between the outer and inner skins; (2) optimising the positions of shading devices in DSF; and (3) adjusting the sizes of openings for better ventilation in the cavity. Su et al. [13] conducted CFD simulations and optimised the DSF design parameters for improving its thermal performance during cooling season in different climatic zones in China. They found that by increasing the width of the cavity resulted in larger total heat gain under all climatic zones except in hot-summer and warm-winter regions. By changing the distance between the outer glass skin and the shading blind had little influence on the DSF total heat gain in all climatic zones. They however concluded that the type and size of ventilation adjustment opening in the DSF did affect the heat gain in a more complex way and should therefore be carefully designed. Although the above approach of geometric optimisation can be effective in the thermal improvement of DSF at the design stage, it can hardly be used for existing DSF buildings. There is therefore the need for more flexible methods of removing excess heat gains in DSFs for applications in both existing and future buildings. 
Literature reviews have hitherto shown that three flexible DSF integrations can be utilised with great potential of eliminating overheating problems: (1) utilisation of shading devices (venetian blinds as the most commonly used one [14]); (2) application of thermal mass and insulation layers; and (3) integration of new materials (such as photovoltaic layers (PV) and phase change materials (PCM). Regarding shading devices, Sun, et al. [15] conducted CFD simulations and experiments on the thermal performance of a DSF with an interstitial aluminium venetian blind and achieved improvement in the U-value of DSF with the blind. Wang, et al. [16] proposed and validated a mathematical model for calculating the solar heat gains through DSF with a venetian blind, and found that the slat angle and shining factor greatly influenced the solar heat gains of the DSF. However, these conventional aluminium venetian blinds have problems caused by high surface temperature during warm seasons, which may lead to large secondary thermal transmittance thus resulting in extra energy consumption in adjacent indoor spaces [17]. In order to avoid the occurrence of high blind surface temperatures, a system with cooling pipes embedded in venetian blinds was proposed and evaluated by Shen et al. [18]. Although the performance of the system was found to be satisfactory in reducing the solar heat gain of DSF in summer, the circulation of cooling water in the pipes is practically complicated and requires a mechanical system which would consume extra energy.

Some studies concerning the use of thermal mass and insulation layers in DSFs have also been reported. Fallahi, et al. [19] assessed the energy performance of DSF with three configurations of concrete thermal mass (thermal mass as inner pane, outer pane, and in air cavity) in comparison with DSF that had a conventional aluminium venetian blind. They found that mechanically-ventilated DSF with thermal mass in the air cavity was able to mitigate the overheating problem in cooling season compared with the equivalent venetian blind case and resulted in considerable energy load reduction,. Nevertheless, it should be noted that the concrete thermal mass that the authors used did affect the level of natural illumination through the DSF. Without losing the daylight benefits of DSF, Sun et al. [20, 21] investigated a DSF integrated with parallel slat The short version of the paper was presented at ICAE2018, Aug 22-25, Hong Kong. This paper is a substantial extension of the short version of the conference paper. 
transparent insulation materials (PS-TIM) and achieved satisfactory luminous environment and energy consumption reduction in an office room. However, the PSTIM system was only evaluated in a double-glazed window with narrow cavity. Performance evaluation in DSF with larger air cavity is yet to be studied.

In the area of advanced materials, a number of studies relating to integrated PV and PCM systems with DSFs have been published. For example, Peng et al. [22-24] conducted experimental and numerical studies on DSF with PV panel as outer skin in a subtropical and a cool-summer Mediterranean climate. They concluded that appropriate ventilation mode was very important for the PV-DSF systems to achieve cooling/heating load reduction. However, instead of limiting the overheating issue in the DSF cavity, the study on these PV-DSF systems focused mainly on the impact of the back-surface temperature of PV module on the power generation efficiency, and the influence of PV-DSF thermal performance on PV power generation and energy outputs. By taking both power generation and thermal performance enhancement into consideration, an integrated PV blind DSF (PVB-DSF) system was proposed and investigated by Luo et al. [25]. They evaluated the thermal performance of the PVBDSF system under different ventilation modes, blind angles, and blind spacing, and found out that it was capable of reducing about half of direct solar heat gain in summer as compared with DSF without blinds.

As a type of thermal storage material, PCMs have much higher thermal capacity than traditional construction materials [26] and thus can be used to enhance the thermal performance of building components (such as a façade system) and to shift peak cooling/heating loads in building [27]. They could therefore be employed in improving thermal performance and preventing overheating in DSFs but only few studies on the PCM integrated DSF system have to date been carried out. De Gracia [28-30] conducted numerical and experimental studies on a macro-encapsulated PCM panels in a DSF cavity and established a high potential of the PCM integrated DSF of night free cooling and therefore of reducing the cooling loads of a building. Another study carried The short version of the paper was presented at ICAE2018, Aug 22-25, Hong Kong. This paper is a substantial extension of the short version of the conference paper. 
out by Diarce et al $[31,32]$ investigated the performance of a DSF incorporated with macro-encapsulated PCM embodied in an aluminum sheet as the outer skin. By using a 2D CFD model and a real-scale test facility, they found that the system can achieve a reduction in the level of overheating and an increase in the thermal inertia of the façade when compared with the other four conventional facades. It is however worth stating that these studies were all based on macro-encapsulated PCM systems which may suffer from limitations such as solidification issue, low physical stability, and sometimes leakage problem [33]. On the other hand, micro-encapsulated PCM has attracted more attention in recent years for its stable thermal and physical properties [34, 35], however, to date few studies involving micro-encapsulated PCM integrations in DSFs have been reported.

In addition, although the above studies have shown the ability of PCM for improving the DSF thermal performance, there is little research information on PCM as shading blinds in DSFs. In terms of PCM shading devices in non-DSF buildings, Weinlaeder, et al. [36] utilised macro-encapsulated PCM panels as shading devices for a building and observed some level of temperature reduction in comparison with a conventional blind. Silva, et al. [37] evaluated the thermal performance of PCM window shutter and found the presence of PCM window shutter resulted in more stable space temperature and increased time delay between the imposed external conditions and the internal domain. Despite the effectiveness of PCM shading blinds with conventional windows in improving thermal environment in buildings, the performance of PCM integrated with DSF system is still unknown and evaluation studies in that respect are required.

\subsection{Aim of study}

In order to achieve a better understanding of the thermal performance and identify possibilities of future implementation of PCM blinds in DSF, the aim of this paper is to present the development and thermal performance evaluations on a new PCM blind system integrated in DSF. It mainly focuses on the development methods of a microencapsulated PCM blind and the experimental evaluation of its thermal performance in The short version of the paper was presented at ICAE2018, Aug 22-25, Hong Kong. This paper is a substantial extension of the short version of the conference paper. 
a DSF test facility. The study originates from our previous theoretical evaluation [38] through computational fluid dynamics (CFD) simulations for the proposed PCM blind system. A prototype of the novel micro-encapsulated PCM blind system was developed through a detailed material selection, screening tests, and manufacturing process. Experimental thermal performance assessment of the developed PCM blind integrated in DSF system were conducted under summer conditions by using a test facility installed in a real DSF building. The experimental data was used to validate the thermal modelling and simulation of the developed system. Guidelines for optimising the operational parameters of the PCM blind system are also provided. To the best of the authors' knowledge, no similar experimental investigation on a DSF integrated with PCM blind system has been previously proposed, especially with a micro-encapsulated PCM blind. Therefore, this paper is intended to fill the gap in the existing knowledge needed for managing overheating problems in DSFs. The main contribution of the present study is to provide an alternative solution for reducing the overheating problem through passive thermal energy storage in DSF. The comparisons between different design parameters including PCM blind tilt angle and position would bring an extra novel characteristic to the present work.

\subsection{Case study building}

Fig. 1 shows the Centre for Sustainable Energy Technologies (CSET) building which was selected for the case study. It is a multi-storey DSF building located at the University of Nottingham Ningbo, China. Ningbo city has a longitude of $121^{\circ} 31^{\prime}$ and a latitude of $29^{\circ} 52^{\prime}$ and it belongs to the hot-summer and cold-winter climatic zone in China where DSF is expected to be preferable in winter and mid-season but would suffer from overheating problems in summer. The double skin facade occupies the south facing side of the building from the first to the fifth floor. On sunny days during the summer period, the air openings at the bottom and on top of DSF are fully opened to create buoyancy driven airflow in the air cavity and evacuate hot air through the top outlet. On rainy days, the air outlet on top is closed to prevent the rain from leaking into DSF cavity. On weekends, all the DSF air openings of CSET building are closed for 
safety reasons. Based on the above conditions, only the sunny weekdays have a normal DSF summer operation mode and are included in the DSF data collection period of this study.
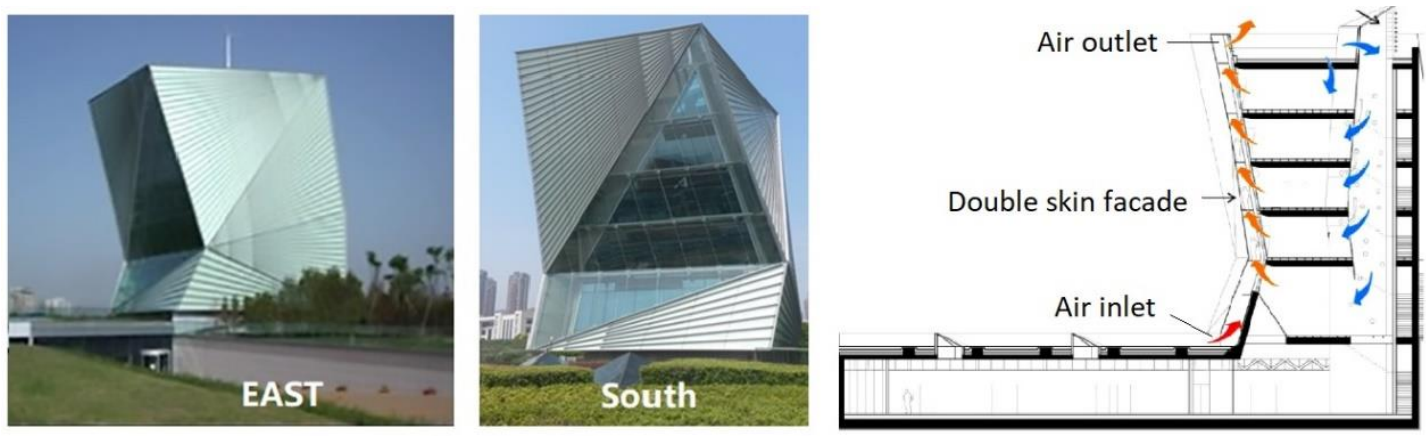

Figure 1: The CSET building and the DSF ventilation mode in summer (red arrows)

On-site meteorological data including ambient air temperature, wind speed and direction, and solar radiation were recorded continuously by a weather station and a pyranometer located on the green roof of the CSET building as shown in Fig. 2. Except for rainy days and weekends, the DSF data records of cavity air temperature and airflow velocity on different floors were recorded by a data monitoring system consisting of computer, data logger, and sensors as presented in Fig. 3. The collected weather and DSF data were used for selecting a PCM at design stage and defining boundary conditions for CFD modelling and simulation.
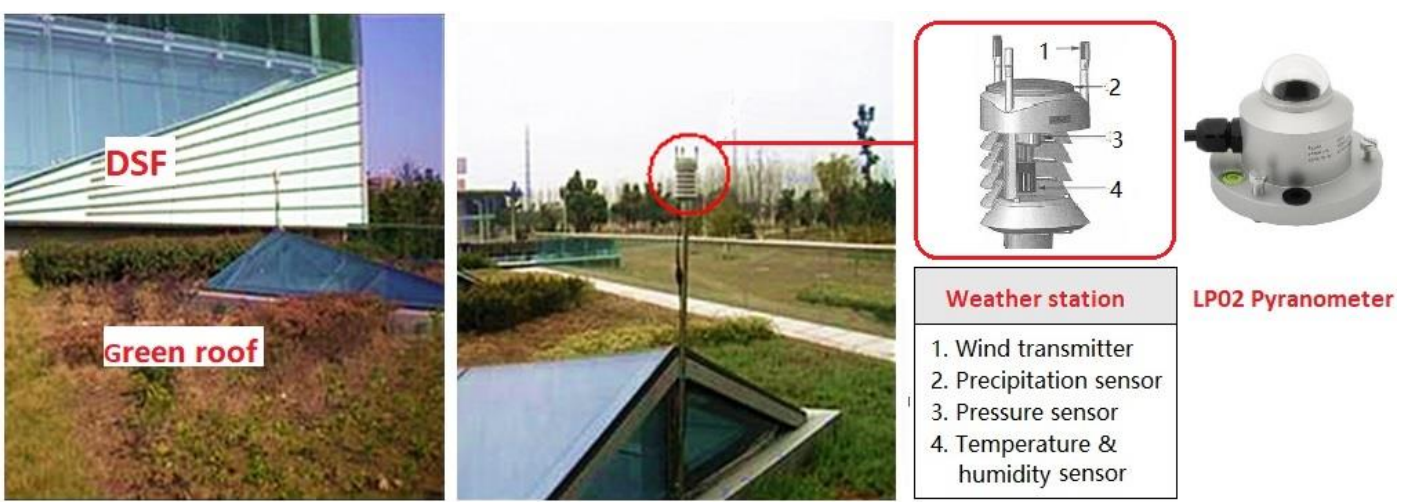

Figure 2: Weather data measurements set-up on the green roof 


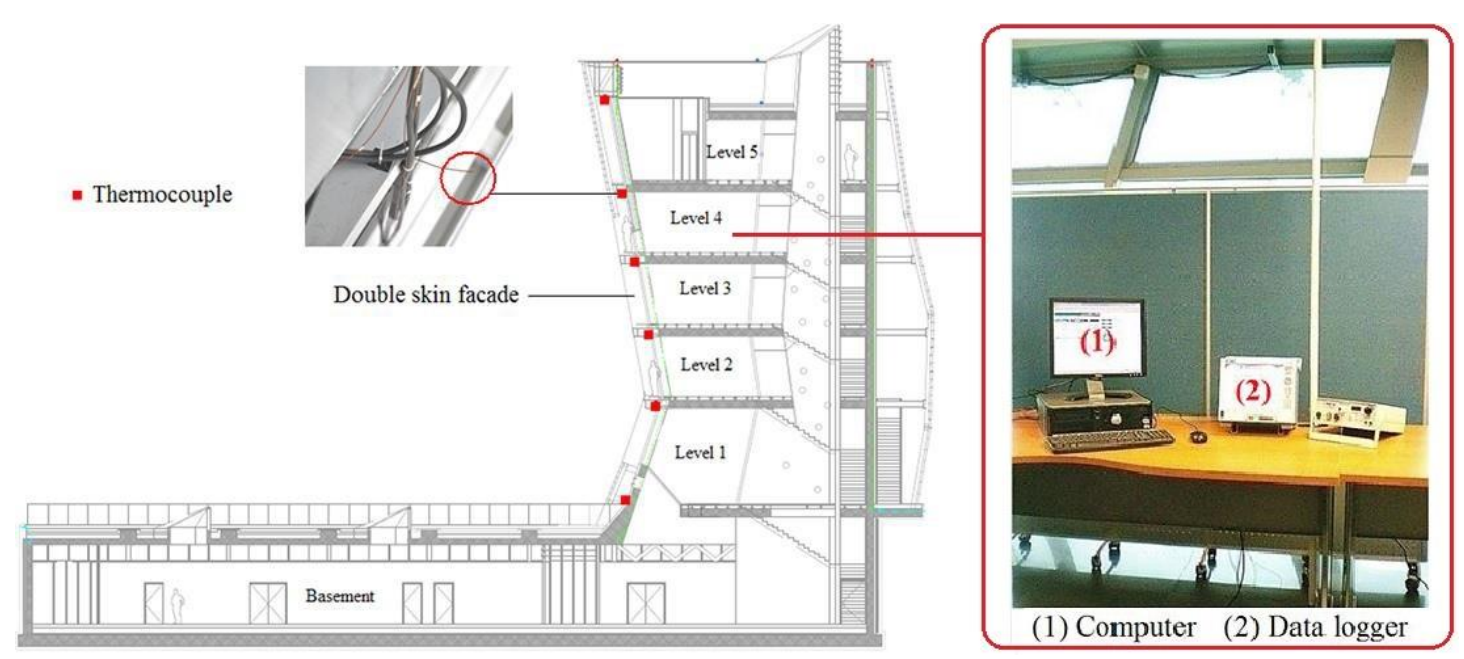

Figure 3: Schematic diagram of DSF data measurements set-up

\section{System development}

\subsection{System description}

Since laminated composite PCM with narrow phase-change zone was much more thermally effective than randomly mixed PCMs [39, 40], we have developed a multilayer blind structure consisting of laminated composite micro-encapsulated PCM blade for DSF. The cross-section diagram of the proposed system is presented in Fig. 4. The tilt angle of the PCM blind corresponds with the local latitude in order to receive the maximum solar radiation (Fig. 4b). The schematic diagram of the multilayer blind structure is depicted in Fig. 4c. Each blade consists of a laminated composite PCM layer at the top and an aluminium substrate layer at the bottom. The PCM layer is intended to absorb the additional solar heat gain trapped in the DSF cavity in the daytime through the external glass skin and discharge the absorbed heat at night when the temperature in the cavity drops below the PCM solidification temperature. The released heat is supposed to be removed by means of natural ventilation system in the DSF. The thickness of the PCM layer was 3mm which corresponded to the maximum quantity of PCM the aluminium substrate could bear using the experimental technique of this study. 


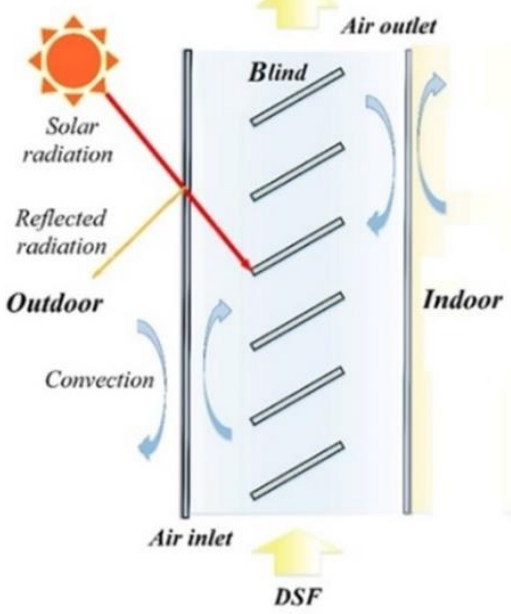

(a)

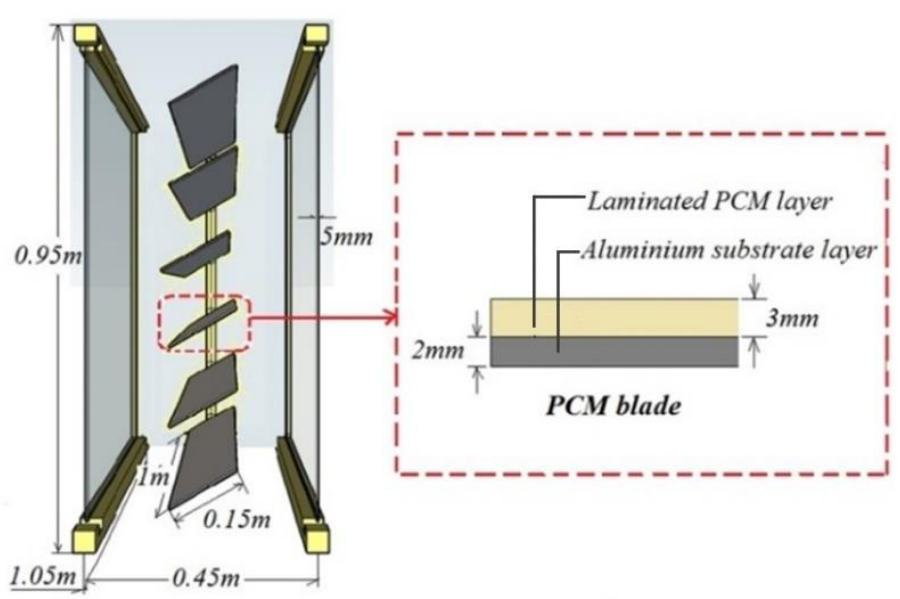

(b)

(c)

Figure 4: Cross-section diagram of DSF integrated with the PCM blind system [38]

\subsection{Material selection}

It is crucial to select suitable PCM in order to achieve a satisfactory performance of the façade system [41]. Among different types of PCMs, organic PCMs are safe, reliable, cheap, and show little sub-cooling or phase segregation problems while having a high latent heat [42]. Therefore the organic PCM was selected since it has large thermal storage capacity, good mechanical stability, and fewer regeneration issues at night time. Once determining the type of PCM, the melting temperature and temperature range of the PCM were identified by using ambient temperature and DSF cavity temperature data obtained from CSET building. Fig. 5 demonstrates the variations of ambient temperature and air temperatures at the third floor in DSF cavity in the summer periods in 2012 and 2013. It can be seen that in general, the variation of the cavity air temperature on the $3^{\text {rd }}$ floor (where the DSF test facility is located) followed a similar trend as the ambient temperature, and most of the temperature values were within the range of $26-40^{\circ} \mathrm{C}$ in both summers. Therefore Rubitherm Company's microencapsulated PCM PX35 was selected for developing the laminated composite PCM blades in this study. Tab. 1 demonstrates the technical data of PX35. It can be seen that the melting temperature range of PX35 can cover most of the summer conditions in the case study. 


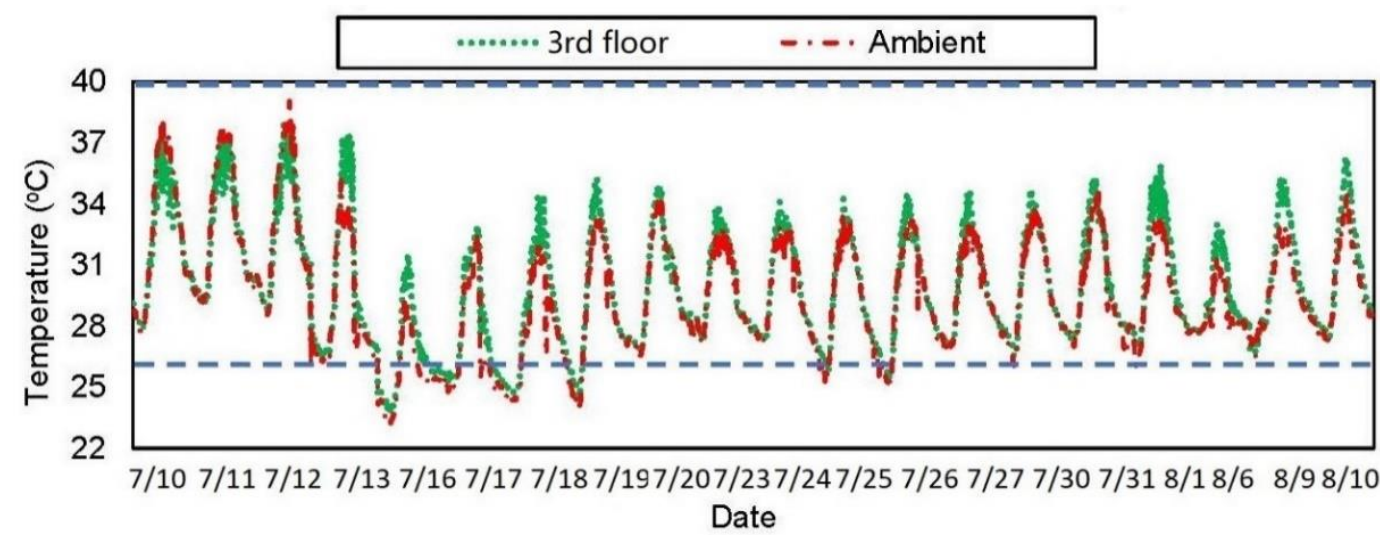

(a) Temperature variation in summer, 2012

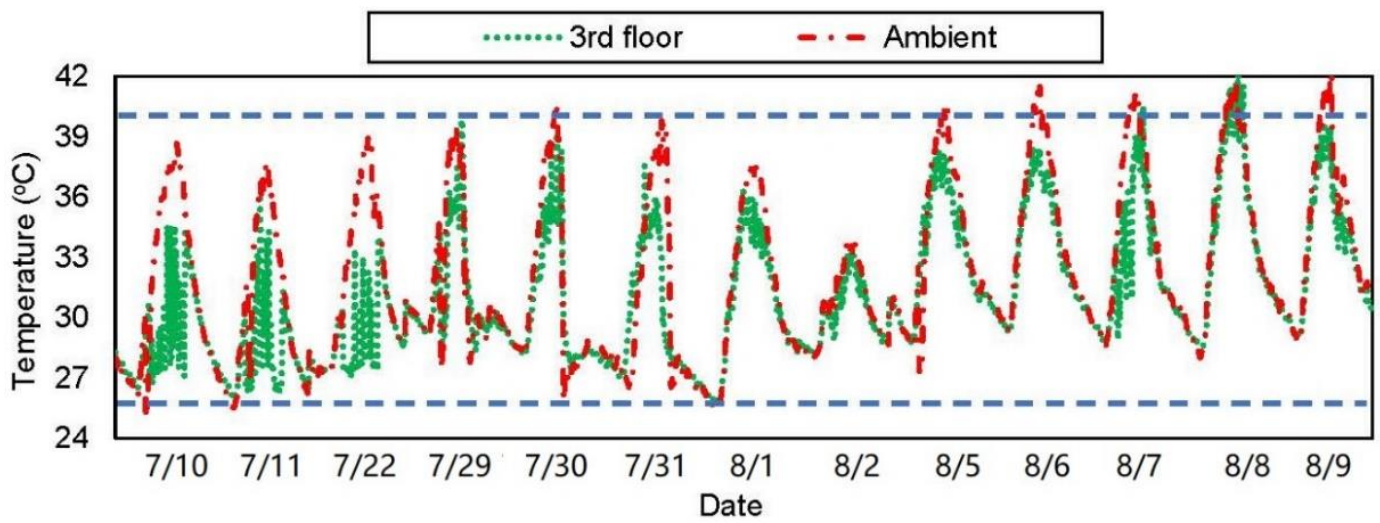

(b) Temperature variation in summer, 2013

Figure 5: Variation of cavity air temperature in DSF during summer period

Table 1 Technical data of PX35 [43]

\begin{tabular}{ccccccc}
\hline Product & $\begin{array}{c}\text { Melting } \\
\text { point } \\
\left({ }^{\circ} \mathrm{C}\right)\end{array}$ & $\begin{array}{c}\text { Melting } \\
\text { range } \\
\left({ }^{\circ} \mathrm{C}\right)\end{array}$ & $\begin{array}{c}\text { Heat of } \\
\text { fusion } \\
(\mathrm{kJ} / \mathrm{kg})\end{array}$ & $\begin{array}{c}\text { Specific heat } \\
\text { capacity } \\
(\mathrm{kJ} / \mathrm{kgK})\end{array}$ & $\begin{array}{c}\text { Density } \\
\left(\mathrm{kg} / \mathrm{m}^{3}\right)\end{array}$ & $\begin{array}{c}\text { Thermal } \\
\text { conductivity } \\
(\mathrm{W} / \mathrm{mK})\end{array}$ \\
\hline PX 35 & 35.00 & $29-36$ & 100.00 & 1.60 & 650.00 & 0.10 \\
\hline
\end{tabular}

\subsection{PCM blade development}

The process of developing PCM blade is demonstrated in Fig. 6. The specific procedures include screening tests on the laminated composite PCM samples, DSC (Differential Scanning Calorimeter) tests to characterise the thermophysical properties of the selected laminated composite PCM, and a manufacturing process of the PCM blade. 


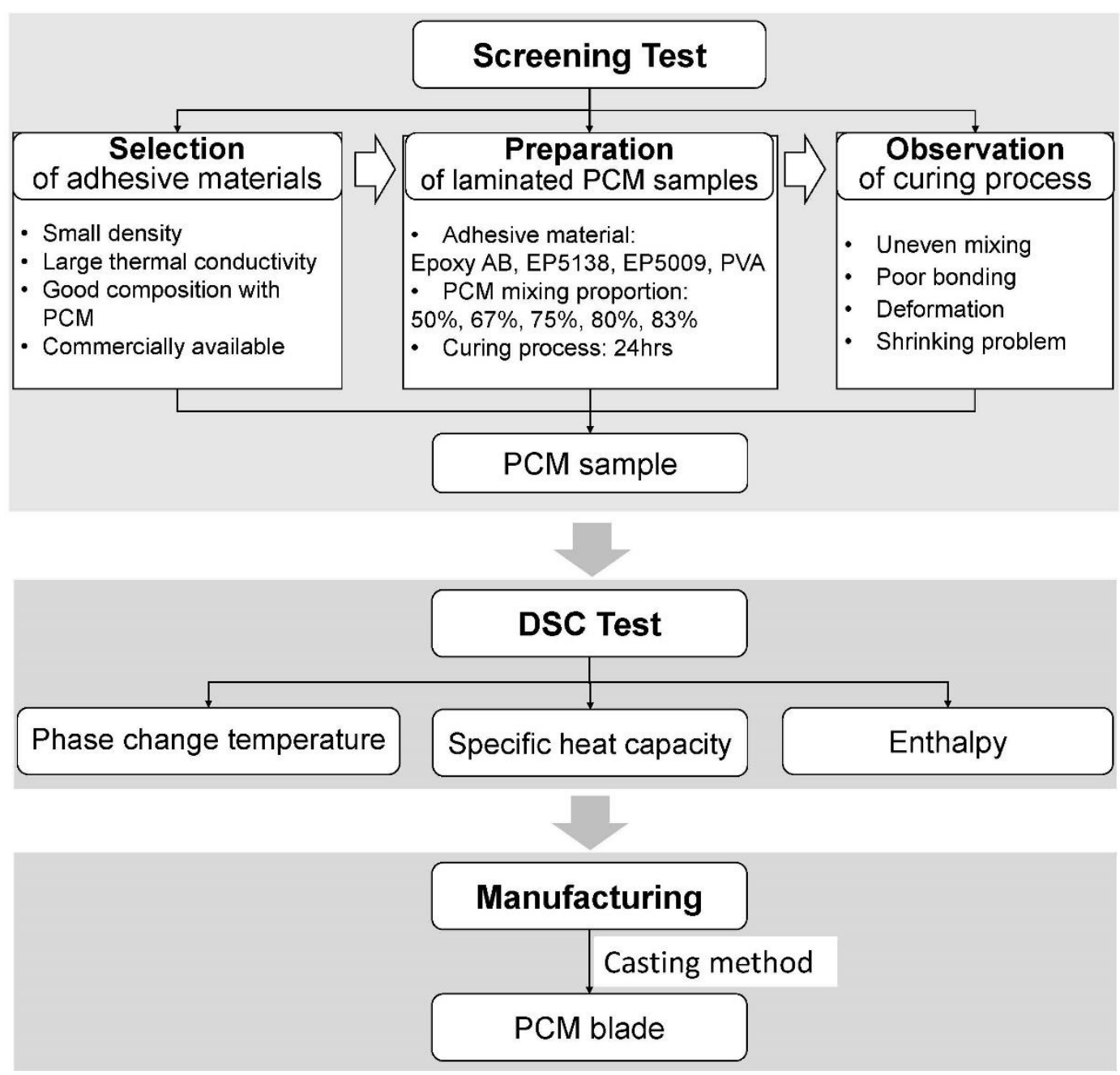

Figure 6: Process of developing the PCM blade

In order to prepare the laminated composite PCM samples, commercially available adhesive materials with small density and large thermal conductivity were selected as bonding material. The selected adhesive materials include three types of epoxy resin material (Epoxy AB, EP5138, and EP5009) and one type of PVA. The laminated composite PCM samples were prepared by mixing the PX35 powders and the selected adhesive materials with different component ratios. The component ratios for each selected adhesive are presented in Tab. 2, and the corresponding prepared samples are demonstrated in Fig. 7. A large PCM mixing ratio in the samples was expected in order to achieve a high thermal storage capacity of the composite material. As shown in Fig. 7, the epoxy resin (EP5138 adhesive and Epoxy AB glue) was the optimal bonding material among these adhesives for larger PCM proportions and had almost no 
deformation and shrinking problem after 24hours curing process. However, we observed that the PCM-epoxy resin samples with PCM ratio higher than 80wt\% suffered from uneven mixing and poor bonding due to the high viscosity of the epoxy resin adhesive. On the other hand, PCM-epoxy resin samples with PCM ratios of lower than $75 \mathrm{wt} \%$ had good bonding effect. Therefore the mixing ratio of $75 \mathrm{wt} \%$ for PCM was selected for developing the laminated composite PCM blade.

Table 2 PCM proportion of laminated composite PCM samples

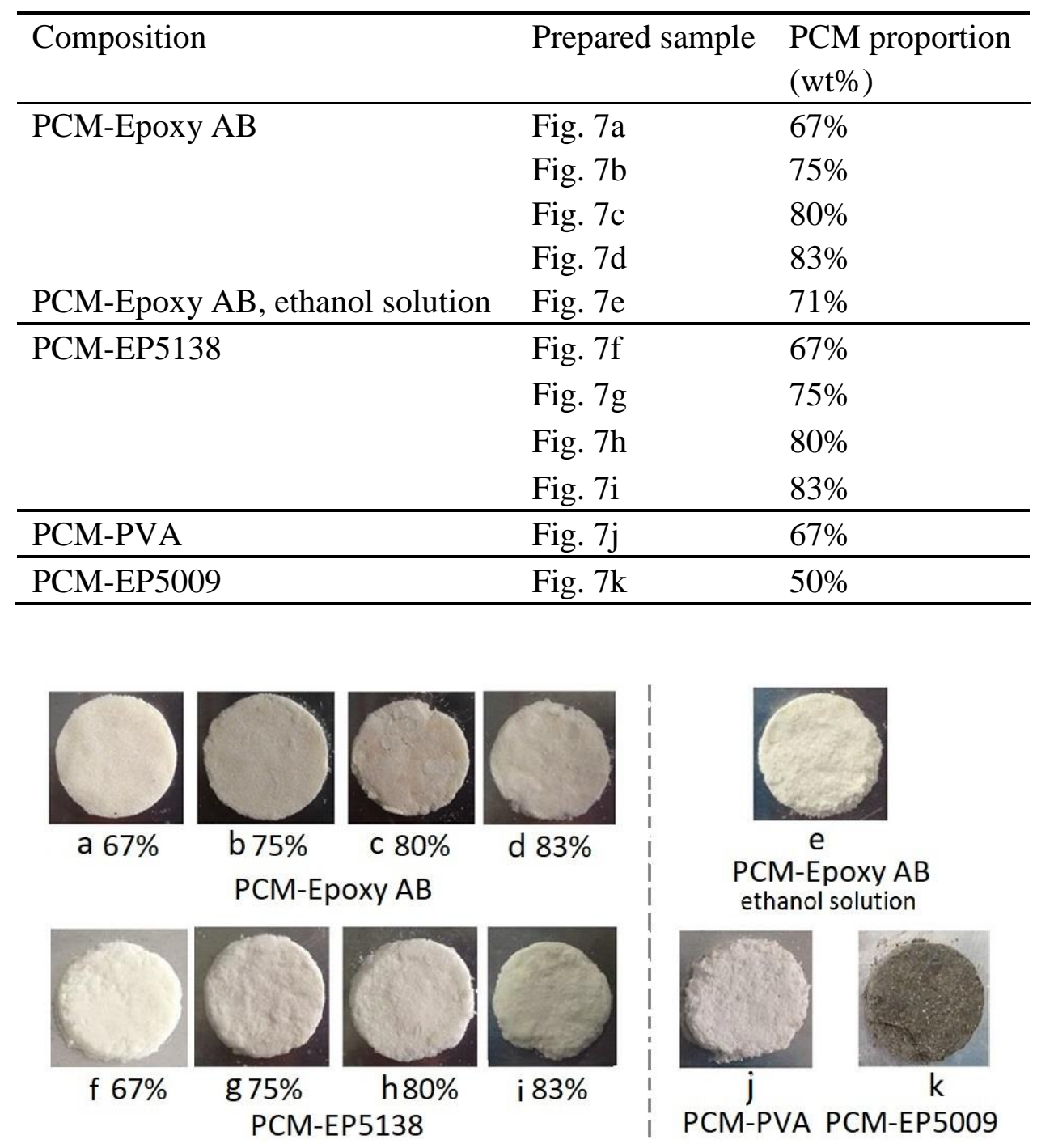

Figure 7: PCM samples with different component ratios

Once the optimal PCM sample was selected, differential scanning calorimetry (DSC) tests were conducted for identifying the thermophysical properties of the selected composite PCM sample. Fig. 8 presents the heat flow and specific heat curves of DSC 
test. The melting temperature range of the composite PCM sample was $28.2-38.5^{\circ} \mathrm{C}$, and its heat of fusion was $77.8 \mathrm{~kJ} / \mathrm{kg}$.

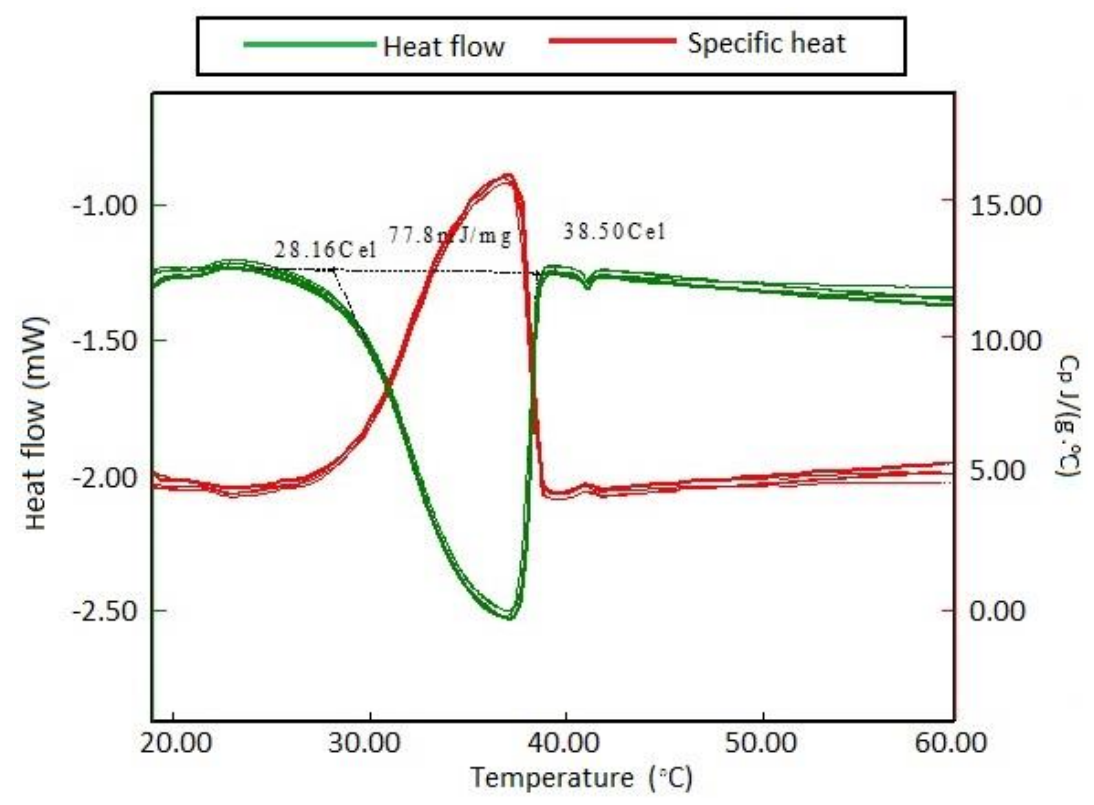

Figure 8: DSC curves for the selected composite PCM sample

In terms of manufacturing process, the PCM blade was produced by using casting method. The mixture of PCM (PX35) powders and preheated liquid epoxy resin adhesive was casted on an aluminium substrate which was fixed in a mould as shown in Fig. 9.

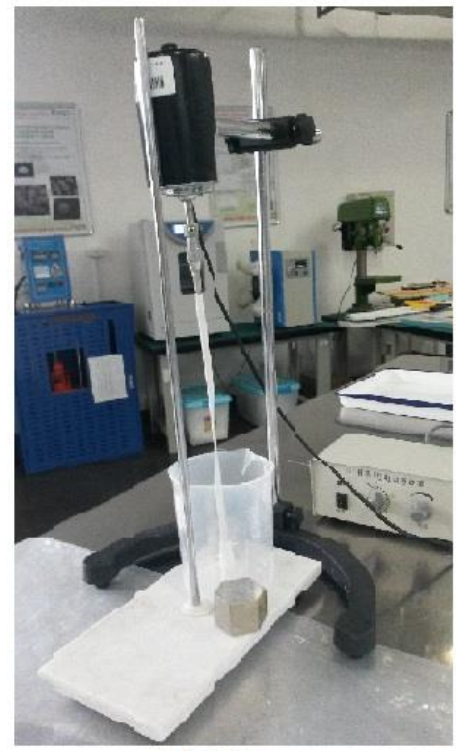

(a) Mixer

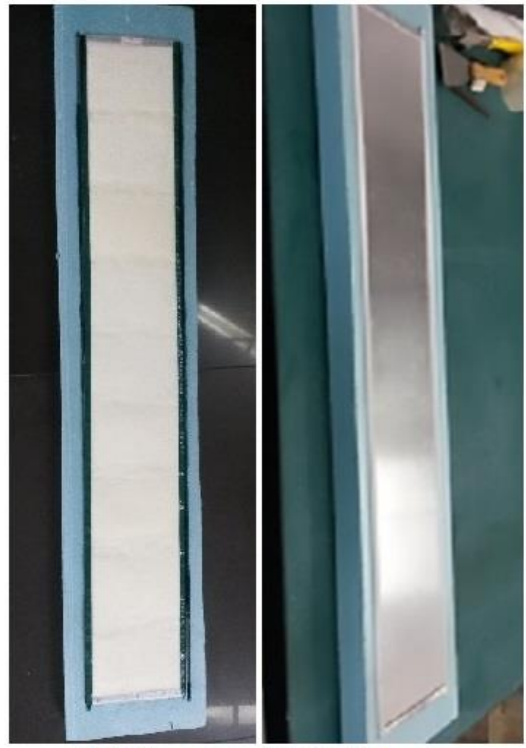

(b) Mould of PCM blade

Figure 9: PCM samples with different component ratios

The short version of the paper was presented at ICAE2018, Aug 22-25, Hong Kong. This paper is a substantial extension of the short version of the conference paper. 


\section{Experimental study}

\subsection{Test facility and experimental set-up}

The DSF scale model test facility was installed on the third floor of the multi-storey DSF in CSET building (see Fig. 10). By installing the test cell on the monitored floor of a real DSF cavity, the airflow and heat transfer behaviour of the real DSF can be directly introduced into the DSF test facility. Compared with previous stand-alone DSF test rig studies [25] or a DSF test rig in an environmental chamber [15], this approach is a new attempt to acquire long-term continuous real-scenario DSF performance data from an in-situ test facility. The DSF scale model test facility was measured at $1.05 \mathrm{~m}$ x $0.95 \mathrm{~m}$ x $0.45 \mathrm{~m}$ with two $5 \mathrm{~mm}$ clear glass walls and two wooden sidewalls. In total there were six PCM blades in the box at a tilt angle of $30^{\circ}$ from horizontal south facing.
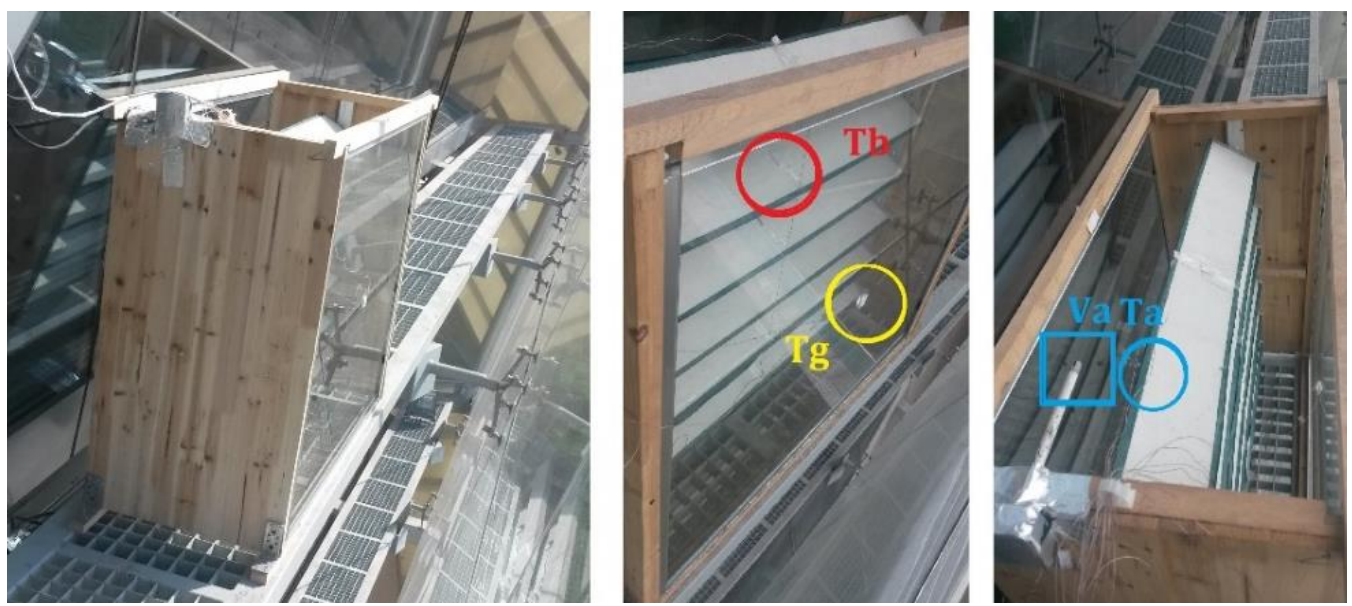

Figure 10: DSF test facility integrated with PCM blind system

(Tb: surface temperature of the blade; Tg: surface temperature of the DSF glass; Ta: air temperature; Va: airflow velocity).

Fig. 11 demonstrates the schematic diagram and experimental set-up of the DSF test facility integrated with PCM blind. The test facility was fully instrumented with temperature and airflow velocity sensors. The data logging system was set up in an office room on the fourth floor. Twenty K-type thermocouples were fixed on the blind/glazing surfaces or in the DSF cavity for measuring the PCM and substrate surface temperature of PCM blind, the interior and exterior surface temperature of glass skins, and the air temperature at different positions in the DSF cavity. Two hotwire 
anemometers were employed at the DSF inlet and outlet to record the inlet/outlet airflow velocity in the DSF test facility. The corresponding symbols used for the sensors and the measured parameters are listed in Tab. 3.

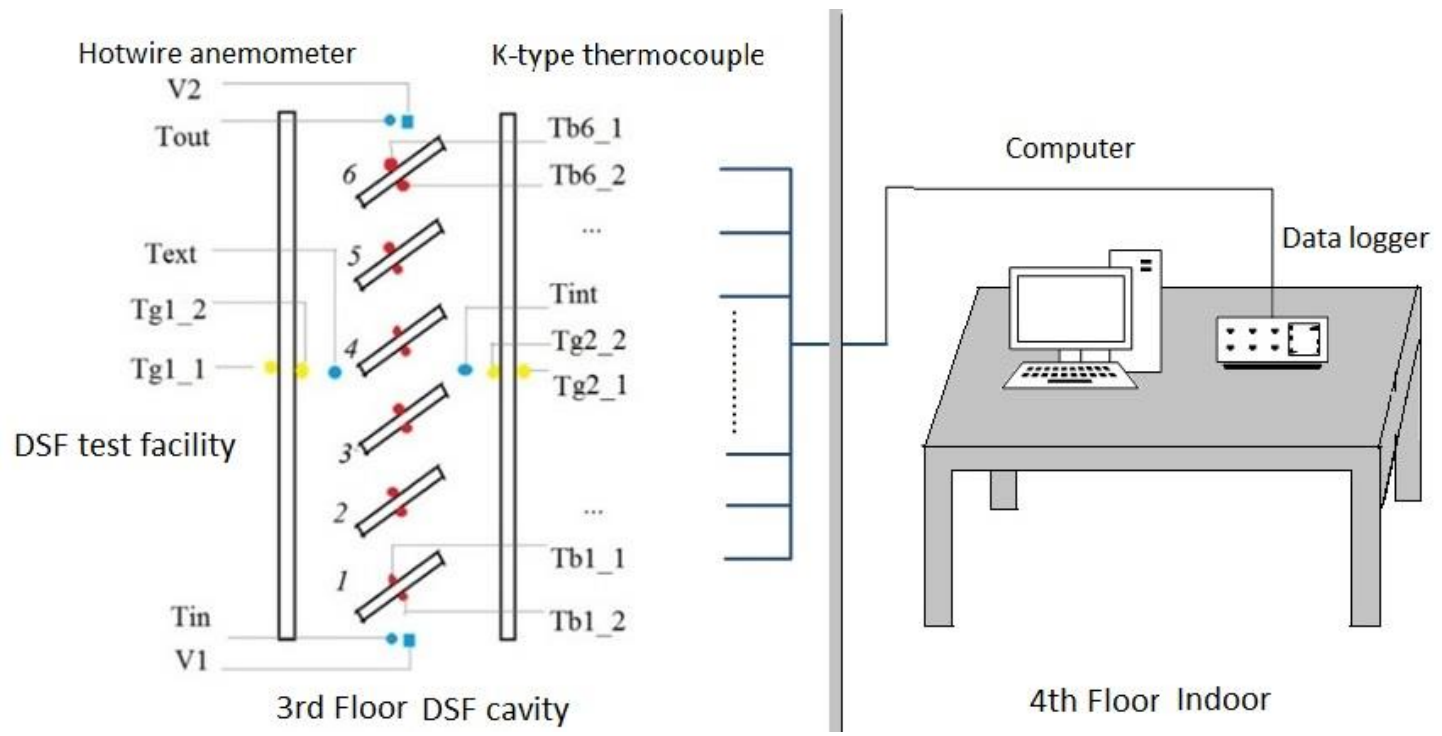

Figure 11: Schematic diagram of DSF test cell experimental set-up

(Red dot $(\mathrm{Tb})$ : thermocouples for measuring blade surface temperature; Yellow dot (Tg): thermocouples for measuring glass surface temperature; Blue dot (Text, Tint, Tin, Tout): thermocouples for measuring air temperature; Blue Square (V1, V2): anemometers for measuring the airflow velocity at the box inlet and box outlet)

Table 3 Parameters to be measured

\begin{tabular}{l|l}
\hline Item & Parameter \\
\hline $\mathrm{T}_{\mathrm{in}}$ & Inlet air temperature \\
$\mathrm{T}_{\mathrm{out}}$ & Outlet air temperature \\
$\mathrm{T}_{\mathrm{ext}}$ & Air temperature close to external glass skin \\
$\mathrm{T}_{\mathrm{int}}$ & Air temperature close to internal glass skin \\
$\mathrm{T}_{\mathrm{g} 1 \_1}$ & Exterior surface temperature of external glass skin \\
$\mathrm{T}_{\mathrm{g} 1 \_2}$ & Interior surface temperature of external glass skin \\
$\mathrm{T}_{\mathrm{g} 2 \_1}$ & Exterior surface temperature of internal glass skin \\
$\mathrm{T}_{\mathrm{g} 2 \_2}$ & Interior surface temperature of internal glass skin \\
$\mathrm{T}_{\mathrm{bx} \_1}$ & Surface temperature of PCM layer, $\mathrm{x}=1-6$ from bottom \\
& to top \\
$\mathrm{T}_{\mathrm{bx} \_2}$ & Surface temperature of substrate, $\mathrm{x}=1-6$ from bottom to \\
$\mathrm{V}_{1}$ & top \\
$\mathrm{V} 2$ & Air velocity at inlet \\
\hline
\end{tabular}

The short version of the paper was presented at ICAE2018, Aug 22-25, Hong Kong. This paper is a substantial extension of the short version of the conference paper. 
All the sensors were calibrated before installation and were connected to the data logging system for continuous data acquisition of the above mentioned ambient weather, DSF, and DSF test facility data. The continuous data collection was conducted in July 2014 except for rainy days and weekends, and the time step of the data collection was 5 seconds. The range and accuracy of the sensors is demonstrated in Tab. 4.

Table 4 Sensors for experimental study and their accuracy

\begin{tabular}{|c|c|c|c|c|}
\hline \multirow{2}{*}{$\begin{array}{l}\text { Sensor } \\
\text { K-type } \\
\text { thermocoupl } \\
\text { e }\end{array}$} & & Parameter & Range & Accuracy \\
\hline & & $\begin{array}{l}\text { Surface temperature of the PCM blind } \\
\text { Surface temperature of the glass skin } \\
\text { Air temperature in cavity of DSF test } \\
\text { facility }\end{array}$ & $1370^{\circ} \mathrm{C}$ & $\pm 3 \%$ \\
\hline $\begin{array}{l}\text { Hotwire } \\
\text { anemometer }\end{array}$ & & $\begin{array}{l}\text { Inlet and outlet airflow velocity of } \\
\text { DSF test facility }\end{array}$ & $0-5 \mathrm{~m} / \mathrm{s}$ & $0.05 \mathrm{~m} / \mathrm{s}$ \\
\hline \multirow[t]{2}{*}{$\begin{array}{l}\text { Weather } \\
\text { station }\end{array}$} & $\begin{array}{l}\text { Temperatur } \\
\text { e sensor }\end{array}$ & Ambient temperature & $-52-60^{\circ} \mathrm{C}$ & $\begin{array}{l} \pm 0.3^{\circ} \mathrm{C} \text { at } \\
+20^{\circ} \mathrm{C}\end{array}$ \\
\hline & $\begin{array}{l}\text { Wind speed } \\
\text { sensor }\end{array}$ & Ambient wind speed & $0-60 \mathrm{~m} / \mathrm{s}$ & $\pm 0.3 \mathrm{~m} / \mathrm{s}$ \\
\hline Pyronameter & & Solar radiation & - & $\pm 5 \%$ \\
\hline
\end{tabular}

\subsection{Experimental Results}

In order to define the overheating scenario during summer period, Fig. 12 demonstrates the ambient environmental data for the monitored days in the summer of 2014 (rainy days and weekends are not included). Among the monitored days, the highest daily temperature on $7 / 11,7 / 12$, and $7 / 21$ exceeded $35^{\circ} \mathrm{C}$, while the highest daily global solar radiation (on the horizontal) on $7 / 20,7 / 21$ was above $1000 \mathrm{~W} / \mathrm{m}^{2}$. The ambient wind speed conditions during the daytime were similar for the four days $7 / 11,7 / 12,7 / 20$, and $7 / 21$. During these days, the highest ambient temperature occurs on $7 / 12$. Therefore $7 / 12$ was chosen to represent the worst scenario of overheating condition, and 7/11, $7 / 20,7 / 21$ were also selected as overheating case studies. 


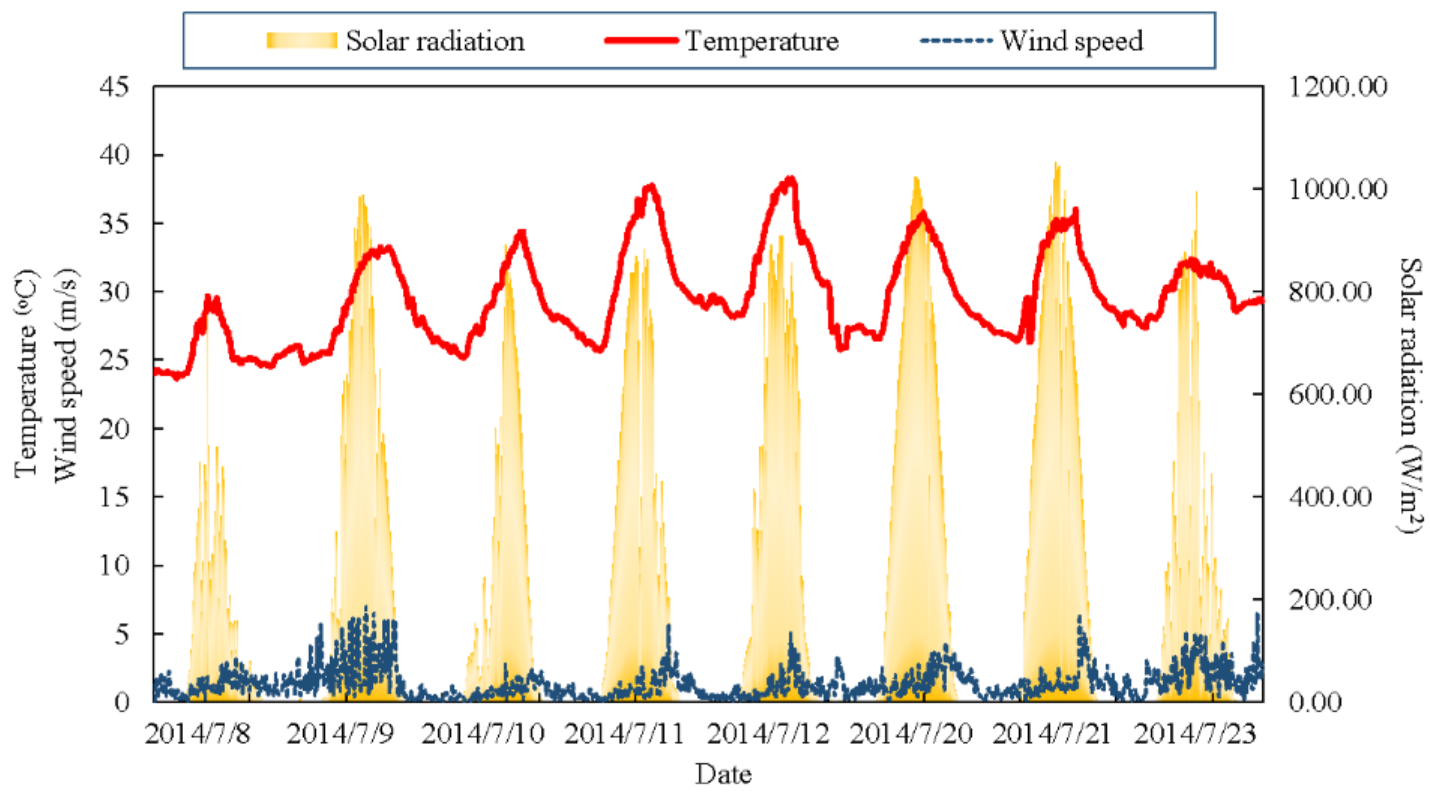

Figure 12: Ambient environmental data for the monitored days in summer, 2014

Fig. 13 presents the air temperature and glass surface temperature data in the DSF test facility on the hottest days $(7 / 11,7 / 12,7 / 20$, and $7 / 21$ in 2014). In general, all the temperature curves at different positions in DSF follow a similar trend. As Fig. 13a shows, the air temperature at different positions in DSF test cell did not exceed $39^{\circ} \mathrm{C}$ during the day time and was below $35^{\circ} \mathrm{C}$ (the melting point) before 10:00 am and after 3:00 pm. This means that the developed PCM blind system in DSF cavity was able to undergo solidification process even on the hottest days in the summer of the studied area. From the peak temperature profile on the hottest day (7/12) of Fig. 13a, it can be seen that the four temperature profiles were not at a distinguishable distance from each other. For most of the time during the measurements, the air temperature at the DSF outlet was the highest while the DSF inlet temperature was the lowest. Similarly, the air temperature near the external glass skin during the peak overheating periods was higher than the air temperature near the internal glass skin. These facts indicate that even on the hottest day, the integrated PCM blind can help stabilise the cavity air temperature and did not cause any additional temperature increase to the cavity air during the peak temperature periods of the day. Fig. 13b compares the interior and exterior surface temperature of external and internal glass. It shows that the surface temperature of the internal glass skin $\left(\mathrm{T}_{\mathrm{g} 2 \_1}, \mathrm{~T}_{\mathrm{g} 2 \_2}\right)$ was about $1.0-2.9^{\circ} \mathrm{C}$ lower than that The short version of the paper was presented at ICAE2018, Aug 22-25, Hong Kong. This paper is a substantial extension of the short version of the conference paper. 
of the external glass skin $\left(\mathrm{T}_{\mathrm{g} 1 \_1}, \mathrm{~T}_{\mathrm{g} 1 \_2}\right)$ during the daytime. As expected, the interior surface temperatures for both skins $\left(\mathrm{T}_{\mathrm{g} 1 \_1}, \mathrm{~T}_{\mathrm{g} 2 \_2}\right)$ were a bit lower than the exterior surface temperatures of the two skins $\left(\mathrm{T}_{\mathrm{g} 1 \_1}, \mathrm{~T}_{\mathrm{g} 2 \_2}\right)$. This shows that the PCM blind system can help prevent the heat from reaching the internal glass wall of the DSF.

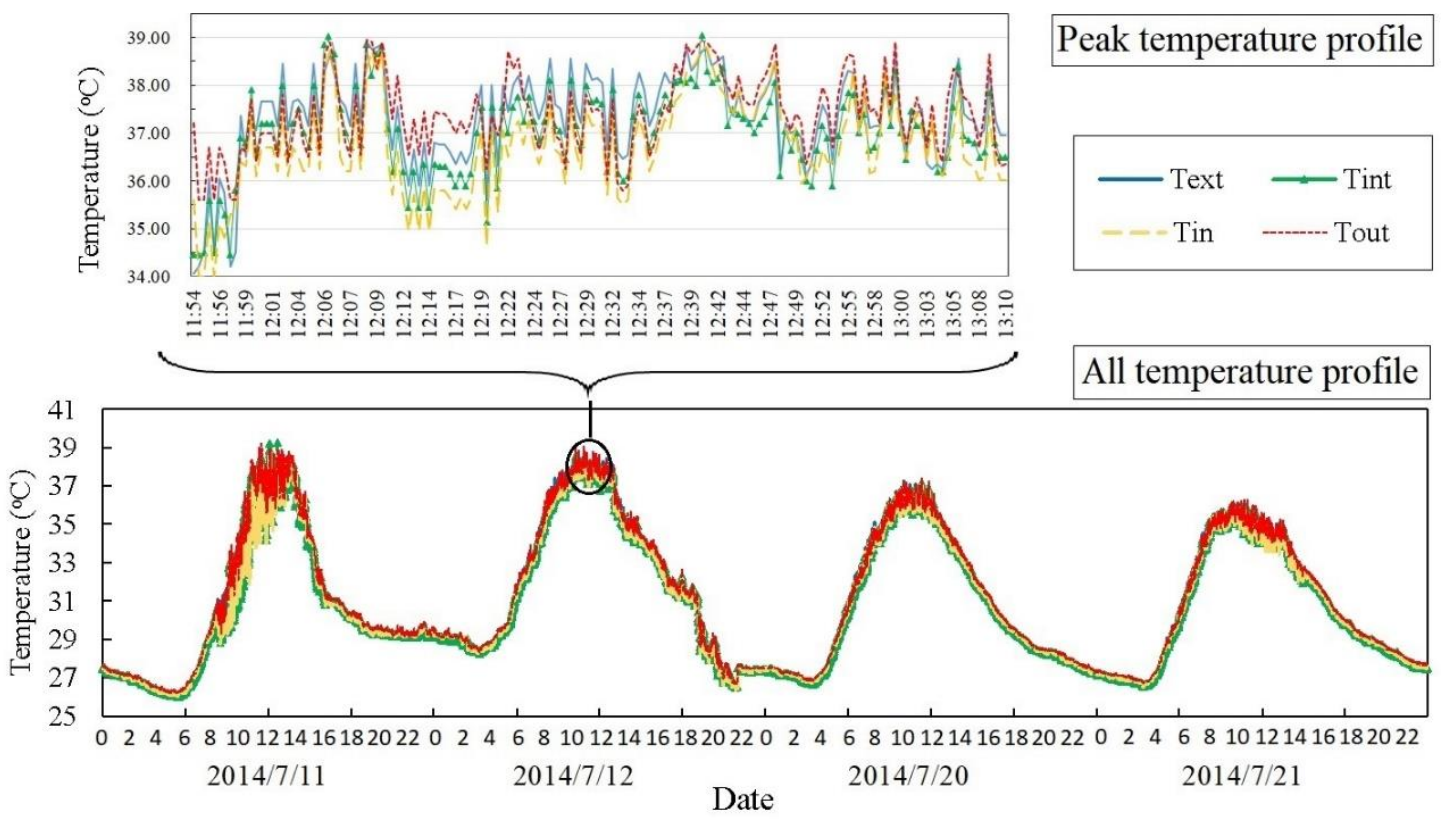

(a) Air temperature in DSF

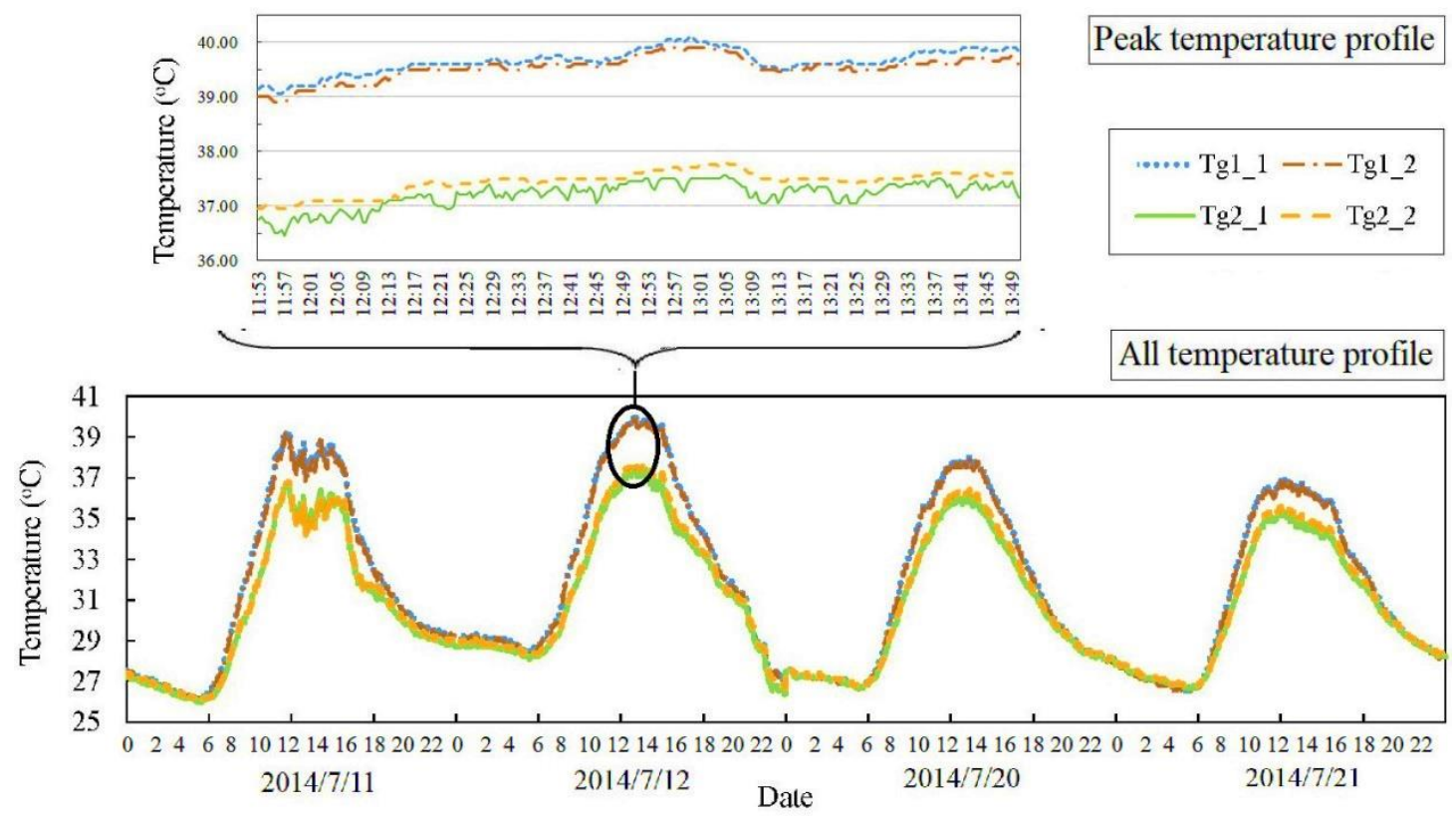

(b) Glass surface temperature of DSF

Figure 13: Temperature data of DSF test facility on 7/11, 7/12, 7/20, and 7/21, 2014 
One of the main improvements that PCM blind intended to bring to DSF was to help reduce the cavity air temperature and the surface temperature of the internal glass in DSF. In order to highlight the impact of PCM blind on the thermal environment in DSF, Fig. 14 shows the daytime average temperature and night-time average temperature profiles of different layers (glass surface temperature, blind surface temperature, and air temperature) in the DSF test cell on the hottest days. The highest DSF air temperature was $35.2^{\circ} \mathrm{C}$ and occurred on $2014 / 7 / 12$. This was only $0.8^{\circ} \mathrm{C}$ higher than the ambient temperature during the daytime of the same day. At night, the average air temperature in DSF ranged from $27.9-29.0^{\circ} \mathrm{C}$ while the ambient temperature had approximately similar values, ranging from $28 \cdot 0-29^{\circ} \mathrm{C}$. With the presence of PCM blind in front of the internal glass skin, the average surface temperature of the internal glass skin $\left(\mathrm{T}_{\mathrm{g} 2 \_1}, \mathrm{~T}_{\mathrm{g} 2 \_2}\right)$ was about $2^{\circ} \mathrm{C}$ lower than the external glass, while the temperature difference between the air close to the external glass $\left(\mathrm{T}_{\mathrm{ext}}\right)$ and the air close to the internal glass skin ( $\mathrm{T}_{\text {int }}$ ) was $0.1-0.5^{\circ} \mathrm{C}$. These measurements indicated that the integrated PCM blind system can act as an additional thermal barrier layer in DSF for reducing heat transferred to the DSF internal skin.

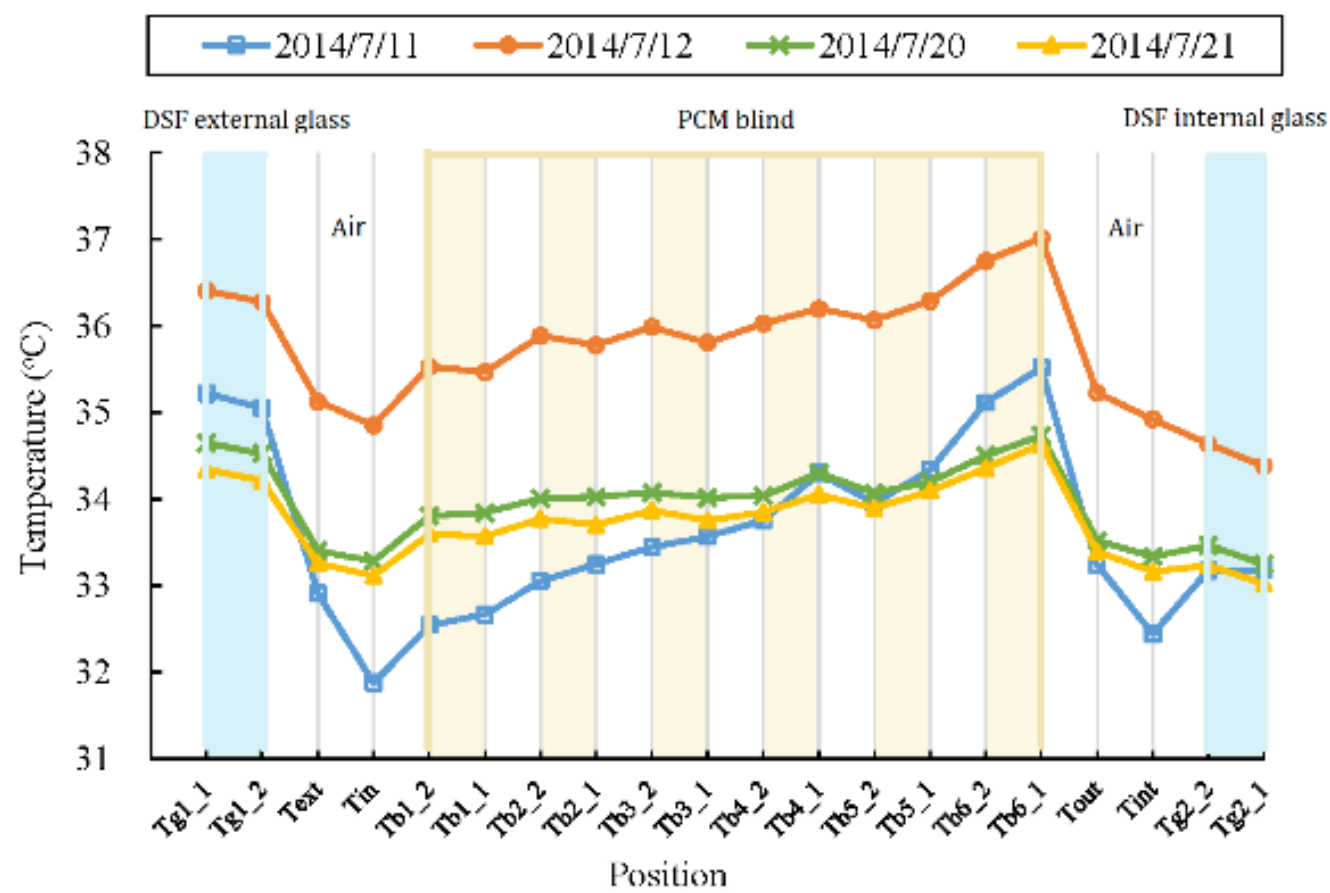

(a) Daytime average temperature profiles 


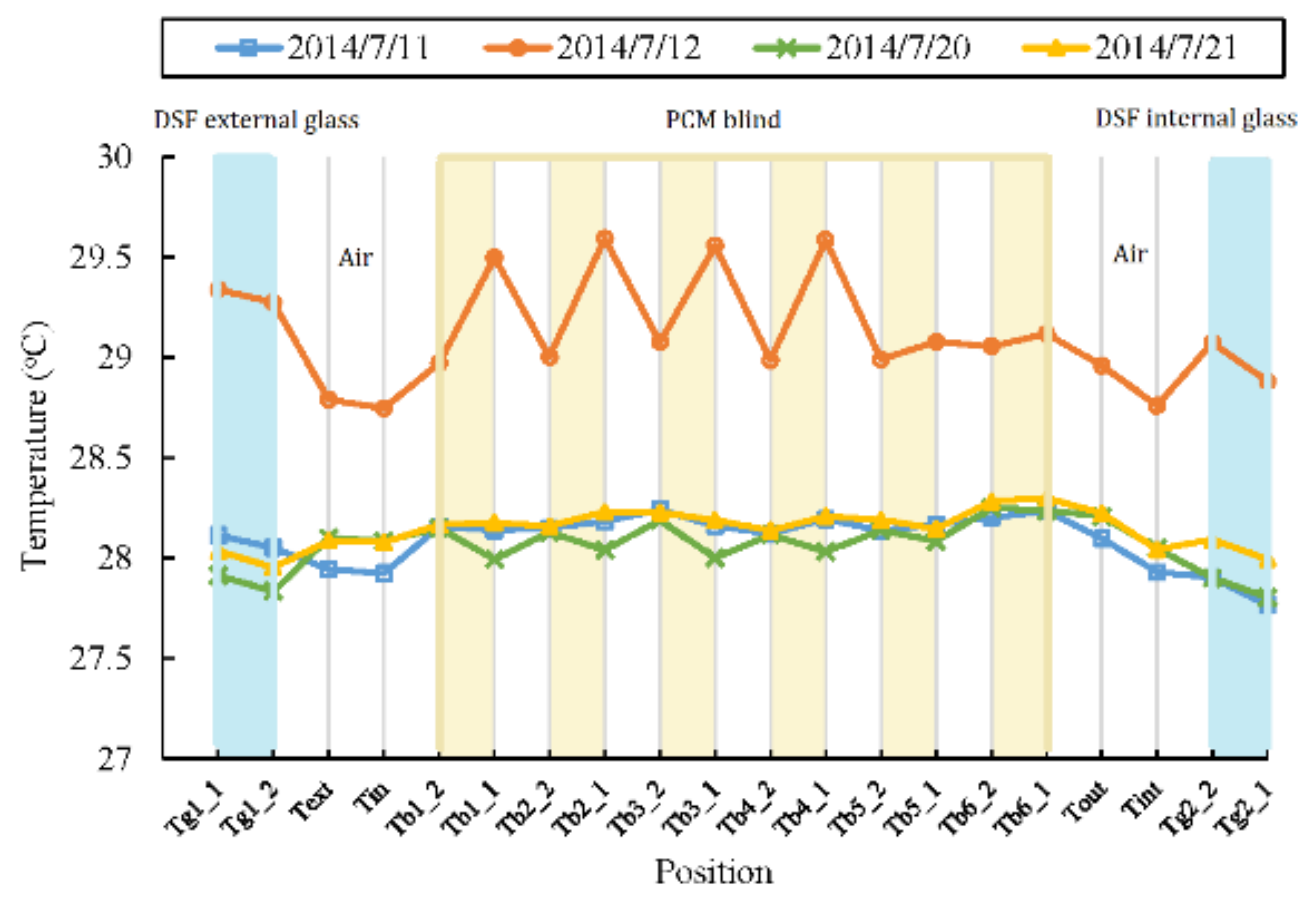

(b) Night-time average temperature profiles

Figure 14: Daytime average and night-time average temperature profiles of different layers in DSF test cell

To identify the influence of ambient environment (average ambient temperature, wind speed, and solar irradiance) on the thermal performance of DSF integrated with PCM blind, the temperature profiles of DSF layers on different days were compared and analysed. Among the four days, high daytime temperatures in all DSF layers (including exterior and interior surfaces of DSF external glass, exterior and interior surfaces of DSF internal glass, top and bottom surfaces of each PCM blades, and cavity air temperature close to DSF external and internal glass) were most frequently occurred on 2014/7/12 during the daytime. Compared with the other three days, the daytime average ambient temperature $\left(34.4^{\circ} \mathrm{C}\right)$ on $2014 / 7 / 12$ was the highest, while the daytime average solar irradiance $\left(454.6 \mathrm{~W} / \mathrm{m}^{2}\right)$ and wind speed $(1.00 \mathrm{~m} / \mathrm{s})$ were comparably low as shown in Tab. 5. This indicates that the ambient temperature was the main influencing factor of DSF layers temperature during the daytime as compared with solar irradiance. The impact of ambient temperature on DSF layers temperature could be further proved by the night-time temperature profiles. Since the ambient air temperatures during the night-time on $2014 / 7 / 11\left(28.1^{\circ} \mathrm{C}\right), 2014 / 7 / 20\left(28.0^{\circ} \mathrm{C}\right)$ and $2014 / 7 / 21\left(28.1^{\circ} \mathrm{C}\right)$ were 
almost the same and no solar irradiance took place at night, the DSF layers temperature profiles were similar for the three days. During the night-time of the three days (2014/7/11, 2014/7/20, 2014/7/21), the PCM was able to undergo a solidification process because the average cavity air temperature $\left(28^{\circ} \mathrm{C}\right)$ was lower than the phase change temperature of PCM. It is evident that the night-time temperature differences between the PCM layer and the substrate on $2014 / 7 / 12$ were a bit larger (about $0.5^{\circ} \mathrm{C}$ ) as compared with the other three days. This larger temperature difference may be due to the low wind speed $(0.8 \mathrm{~m} / \mathrm{s})$ on $2014 / 7 / 12$ which resulted in small cavity air velocity and poor convective heat transfer on the PCM layer surface. Therefore it was more difficult for the stored heat in PCM layer to be released during night-time on 2014/7/12, while the aluminium substrate can be cooled by the cavity air more easily.

Table 5 Daily average ambient weather data for the four days

\begin{tabular}{|c|c|c|c|c|c|c|c|}
\hline \multirow[t]{3}{*}{ Date } & \multicolumn{3}{|c|}{ Temperature } & \multicolumn{3}{|c|}{ Wind Speed } & \multirow{2}{*}{$\begin{array}{l}\text { Total solar } \\
\text { irradiance } \\
\left(\mathrm{W} / \mathrm{m}^{2}\right)\end{array}$} \\
\hline & $\left({ }^{\circ} \mathrm{C}\right)$ & & & $(\mathrm{m} / \mathrm{s})$ & & & \\
\hline & All & Daytime & $\begin{array}{l}\text { Night- } \\
\text { time }\end{array}$ & All & Daytime & $\begin{array}{l}\text { Night- } \\
\text { time }\end{array}$ & Daytime \\
\hline 7.11 & 30.9 & 33.7 & 28.1 & 1.02 & 1.36 & 0.68 & 443.0 \\
\hline 7.12 & 31.7 & 34.4 & 29.0 & 1.00 & 1.20 & 0.80 & 454.6 \\
\hline 7.20 & 30.4 & 32.7 & 28.0 & 1.50 & 1.85 & 1.14 & 570.6 \\
\hline 7.21 & 30.3 & 32.6 & 28.1 & 1.30 & 1.65 & 0.95 & 566.1 \\
\hline
\end{tabular}

To further justify the influence of ambient environment, the correlations between the meteorological parameters (ambient temperature, solar irradiance, and wind speed) and the DSF layers temperature were demonstrated in Fig.15. The linear regression slopes and correlation coefficients $\left(\mathrm{R}^{2}\right)$ are presented in Tab.6. The ambient temperature-DSF layers temperature correlation regression lines show the highest slopes and correlation coefficients which indicates the DSF layers temperature increased with the increase in ambient temperature. The correlation coefficients of solar irradiance-DSF layers temperature are also high with values above 0.6 which shows certain level of impact of solar irradiance on DSF layers temperature. As expected, the DSF layers temperature 
increases with higher solar irradiance. It can be also noticed that the DSF layers temperature values do not significantly change with outdoor wind velocity during the monitored period and this is shown by the lowest correlation coefficients. Due to the low recorded wind speeds in the area the DSF layers temperatures were not impacted by the wind speed. The above discussion indicates that the ambient air temperature had significant impact on the magnitude of temperature of all the layers in DSF.
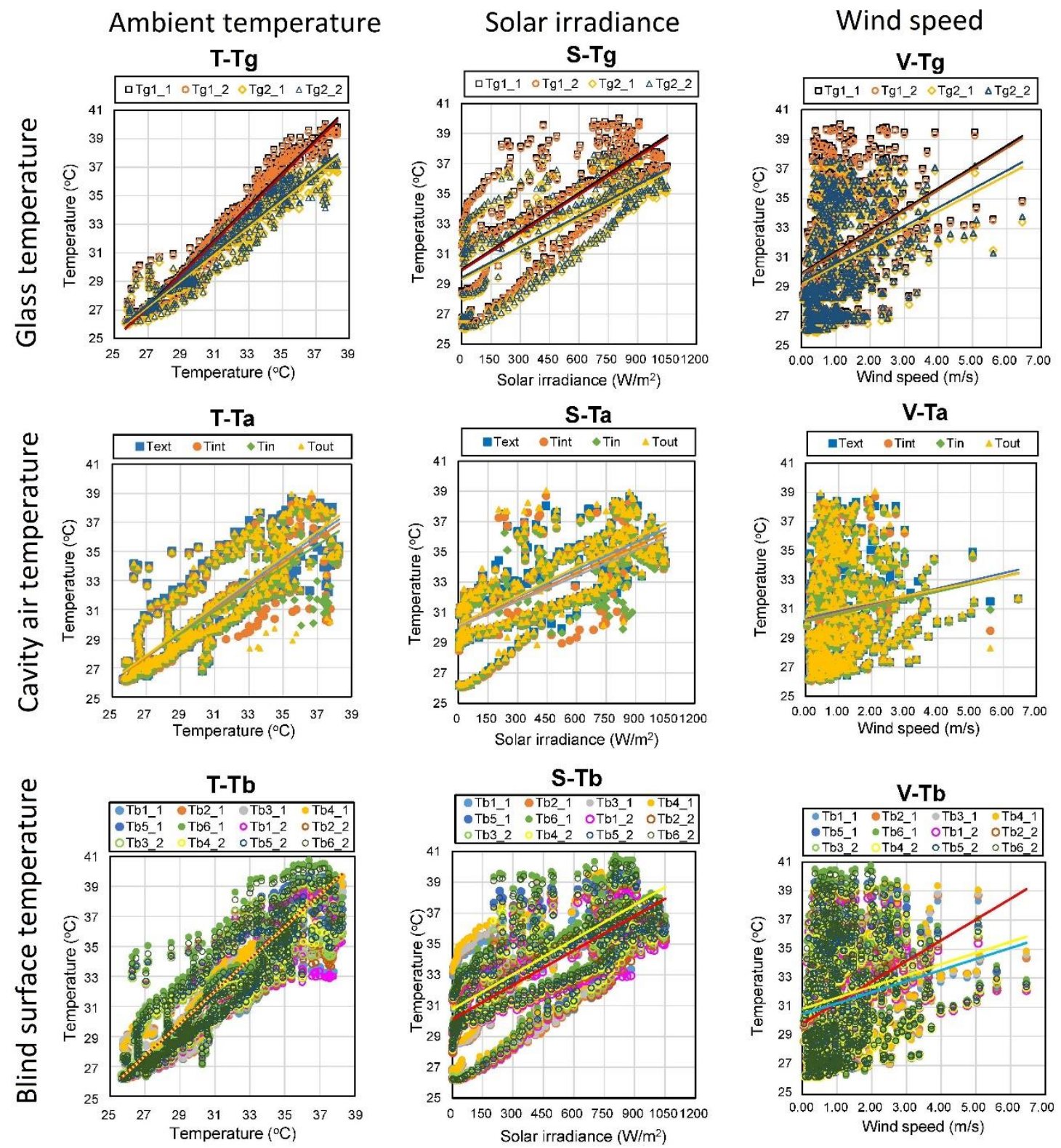

Figure 15: Daytime average and night-time average temperature profiles of different layers in DSF test cell 
Table 6 Linear regression slope and correlation coefficients of meteorological parameters and PCM layers temperature

\begin{tabular}{|c|c|c|c|c|c|c|c|}
\hline \multirow[t]{2}{*}{$\begin{array}{l}\text { DSF layer } \\
\text { temperature }\end{array}$} & & \multicolumn{2}{|c|}{$\begin{array}{l}\text { Ambient } \\
\text { temperature }\end{array}$} & \multicolumn{2}{|c|}{$\begin{array}{l}\text { Total solar } \\
\text { irradiance }\end{array}$} & \multicolumn{2}{|c|}{ Wind speed } \\
\hline & & Slope & $\mathrm{R}^{2}$ & Slope & $\mathrm{R}^{2}$ & Slope & $\mathrm{R}^{2}$ \\
\hline \multirow{4}{*}{ Glass } & $T g 1 \_1$ & 1.1670 & 0.9631 & 0.5445 & 0.6977 & 1.4281 & 0.108 \\
\hline & $T g 1 \_2$ & 1.1560 & 0.9620 & 0.5431 & 0.6961 & 1.4164 & 0.1087 \\
\hline & $T g 2 \_l$ & 0.9306 & 0.9463 & 0.5237 & 0.6685 & 1.2127 & 0.1209 \\
\hline & $T g 2 \_2$ & 0.9353 & 0.9373 & 0.5186 & 0.6642 & 1.2482 & 0.1256 \\
\hline \multirow{4}{*}{ Cavity air } & Text & 0.8400 & 0.7172 & 0.5024 & 0.6996 & 0.5215 & 0.0208 \\
\hline & Tint & 0.8148 & 0.6925 & 0.4614 & 0.6724 & 0.5043 & 0.0200 \\
\hline & Tin & 0.7618 & 0.6639 & 0.4803 & 0.6831 & 0.5158 & 0.0229 \\
\hline & Tout & 0.8531 & 0.7097 & 0.5004 & 0.6965 & 0.4440 & 0.0145 \\
\hline \multirow{12}{*}{$\begin{array}{l}\text { Blade } \\
\text { surface }\end{array}$} & Tb1_1 & 0.9437 & 0.8868 & 0.4908 & 0.6328 & 1.3540 & 0.1373 \\
\hline & $T b 2 \_1$ & 0.9967 & 0.9026 & 0.4715 & 0.6216 & 1.4319 & 0.1402 \\
\hline & Tb3_l & 1.0205 & 0.9177 & 0.4765 & 0.6282 & 1.4209 & 0.1339 \\
\hline & Tb4_1 & 1.0715 & 0.9416 & 0.4834 & 0.6465 & 1.4308 & 0.1263 \\
\hline & Tb5_1 & 1.0193 & 0.8345 & 0.5530 & 0.7248 & 0.8078 & 0.0394 \\
\hline & Tb6_l & 1.1126 & 0.8121 & 0.5507 & 0.7281 & 0.7649 & 0.0289 \\
\hline & Tbl_2 & 0.8528 & 0.7516 & 0.5437 & 0.7167 & 0.6621 & 0.0341 \\
\hline & $T b 2 \_2$ & 0.9113 & 0.7764 & 0.5425 & 0.7178 & 0.7001 & 0.0345 \\
\hline & Tb3_2 & 0.9340 & 0.7951 & 0.5450 & 0.7194 & 0.7092 & 0.0345 \\
\hline & Tb4_2 & 0.9654 & 0.8135 & 0.5538 & 0.7265 & 0.7518 & 0.0371 \\
\hline & Tb5_2 & 0.9776 & 0.8201 & 0.5497 & 0.7246 & 0.7623 & 0.0375 \\
\hline & $T b 62$ & 1.0744 & 0.8191 & 0.5431 & 0.7241 & 0.7690 & 0.0316 \\
\hline
\end{tabular}

The heat transfer direction within each PCM blade can be justified by the temperature difference between the PCM and substrate surfaces. Fig. 16 presents the profiles of temperature differences between the surfaces of PCM layer and the substrate for different blades on the monitored days. It shows that during most of the daytime, the surface temperature of PCM layers was higher than the substrates. This ensured that the direction of the heat transfer process was from the PCM layers to the substrates within the blade during melting process. At night-time, the surface temperature of PCM layers was lower than the substrates which indicated a heat transfer direction from the substrate to the PCM layer during heat releasing process of the blade. 


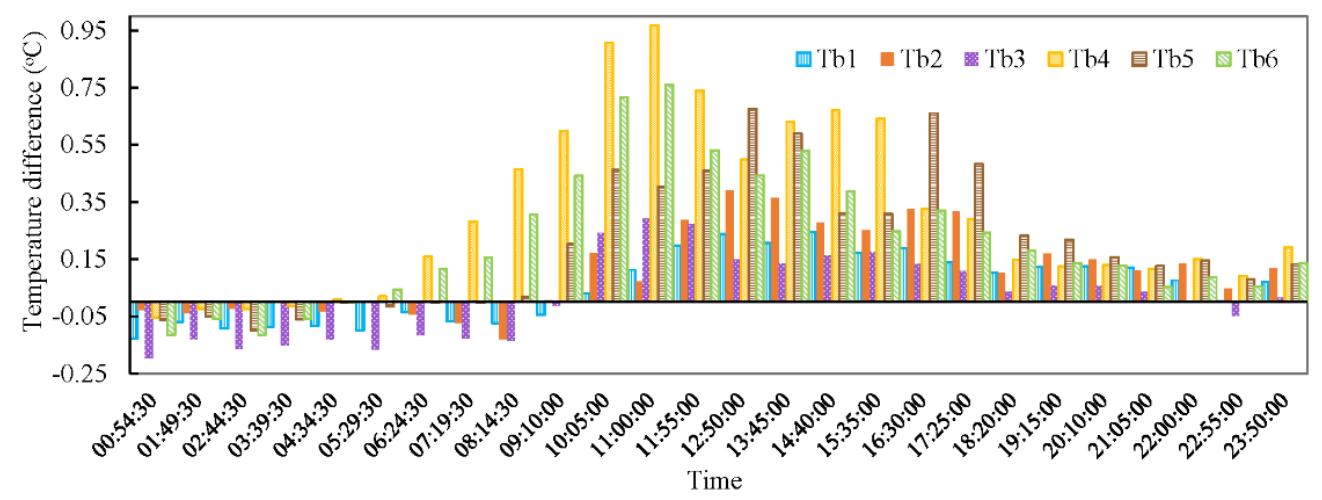

(a) Temperature differences on $2014 / 7 / 11$

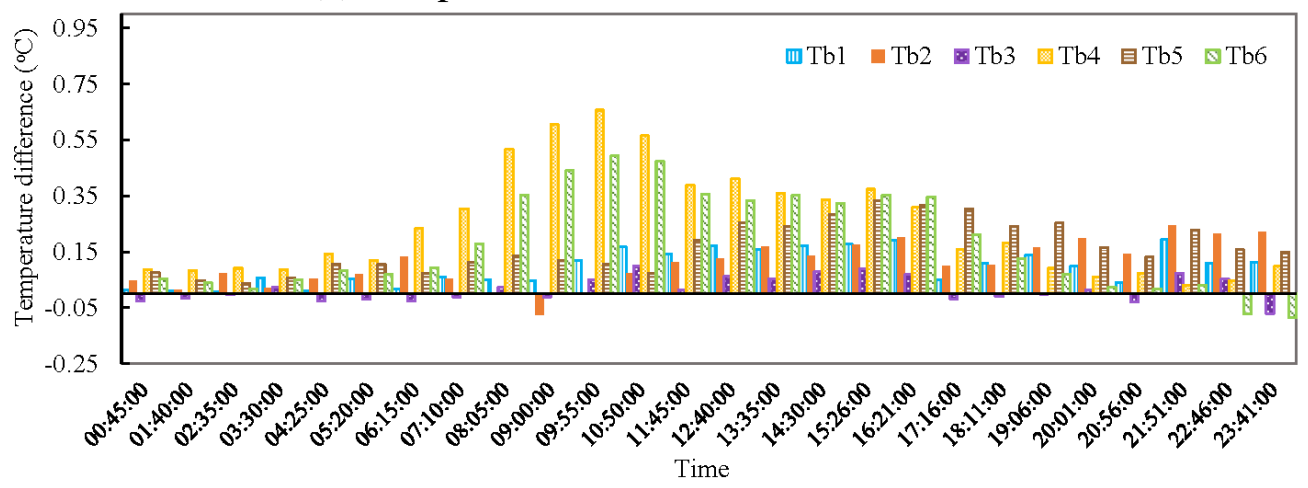

(b) Temperature differences on 2014/7/12

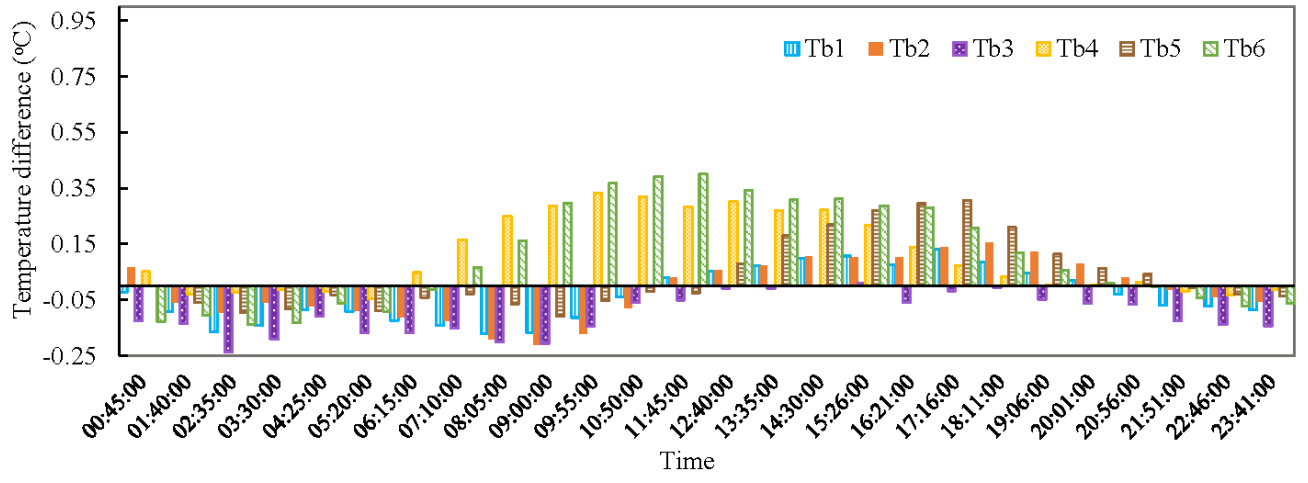

(c) Temperature differences on $2014 / 7 / 20$

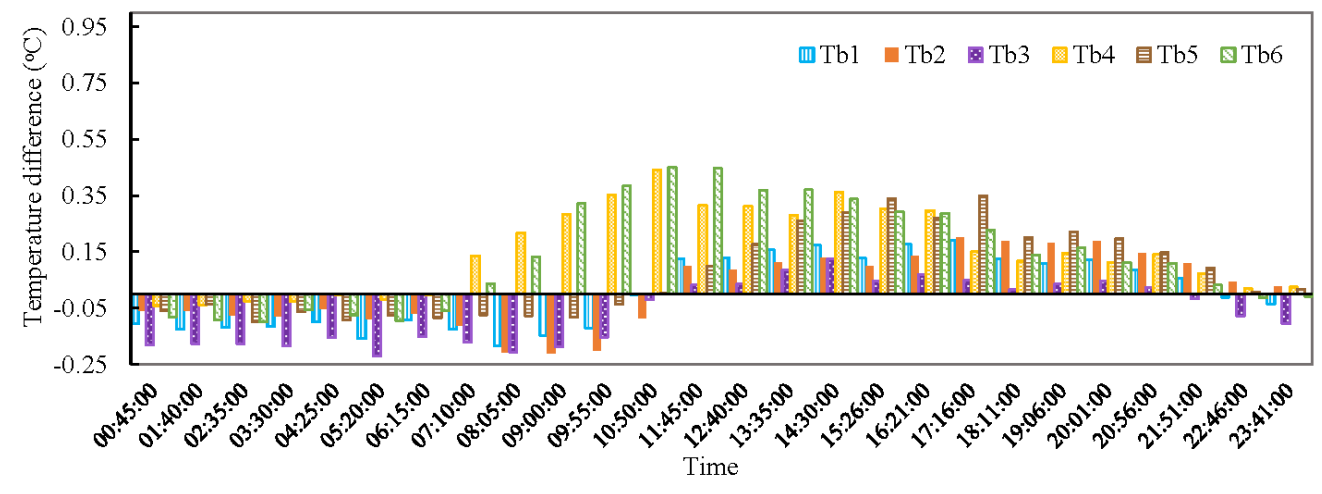

(d) Temperature differences on 2014/7/21

Figure 16: Temperature differences of the surfaces of PCM layer $\left(\mathrm{T}_{\mathrm{bn}_{-} 1}\right)$ and substrate $\left(\mathrm{T}_{\mathrm{bn} \_2}\right)\left(\Delta \mathrm{T}_{\mathrm{bn}}=\mathrm{T}_{\mathrm{bn} \_1}-\mathrm{T}_{\mathrm{bn} \_2} ; \mathrm{n}=1,2,3,4,5,6\right)$ 
On different days, the times of the day when the peak temperature difference occurred on the same blade were quite close. For example, the times of the peak temperature difference for the fourth blade on different days were 11:00 on 2014/7/11 (with peak temperature difference of about $1^{\circ} \mathrm{C}$ ), $9: 55$ on $2014 / 7 / 12,9: 46$ on $2014 / 7 / 20$, and 10:31 on 2014/7/21. For the fifth blade, the times of the peak temperature difference on different days were $16: 30$ on 2014/7/11 (with peak temperature difference of about $\left.0.7^{\circ} \mathrm{C}\right), 15: 26$ on $2014 / 7 / 12,16: 11$ on $2014 / 7 / 20$, and $16: 56$ on $2014 / 7 / 21$.

On the same day, the times when the peak temperature differences between the PCM and substrate surface occurred were not the same amongst the different blades. For instance, on 2014/7/11 the peak temperature difference for the fourth blade was about $0.7^{\circ} \mathrm{C}$ and occurred at 9:55, while the peak temperature difference for the fifth blade was about $0.3^{\circ} \mathrm{C}$ and occurred at $15: 26$. On 2014/7/11 the peak temperature difference for the fourth blade was about $1^{\circ} \mathrm{C}$ and occurred at 11:00, while the peak temperature difference for the fifth blade was about $0.7^{\circ} \mathrm{C}$ and occurred at $16: 30$. It should also be noticed that the temperature difference between the PCM and substrate surface for the fourth and the sixth PCM blade was the largest among all the blades, while the smallest temperature difference between the PCM and substrate surface occurred for the first and the third blades. The above observed varied times of peak temperature differences as well as the actual values of the temperatures on the blades were caused by the complex heat transfer among adjacent blades and the surrounding air within the PCM blind system, which may be influenced by the tilt angle and position of the blind. The performance of the PCM blind should be justified in a future study with consideration of different solar incident angles for enhancing the thermal storage efficiency of the integrated system.

To conclude, the experimental results shows the phase transition ability of PCM blind throughout the day, which helps remove excessive heat gains in DSF cavity and accordingly improve the overall thermal performance of the integrated DSF system in summer. Even though these levels of cavity air temperature and glass surface The short version of the paper was presented at ICAE2018, Aug 22-25, Hong Kong. This paper is a substantial extension of the short version of the conference paper. 
temperature were acceptable, the effectiveness of PCM blind in helping to reduce the cavity air temperature needs to be justified by comparing with a conventional aluminium blind case through a numerical study.

\section{Numerical study}

\subsection{Numerical model and model validation}

The numerical model adopted in this study has been developed and validated by our previous work [40]. The simplified airflow and heat transfer process involving convection, conduction, and radiation were given by the assumptions and equations as follows:

- Both convective and radiative heat transfer exist on the surface of the PCM blind.

- Only one-dimensional conduction is considered within each PCM blade and convective heat transfer is negligible.

- The PCM is homogeneous and isotropic with constant thermophysical properties except for its enthalpy.

- The thermophysical properties of the aluminium substrate are constant.

- The airflow in DSF cavity is treated as 2-dimensional incompressible flow.

- There are turbulences in the cavity due to the presence of PCM blades.

- Heat loss by long wave radiation to the surroundings and sky is excluded.
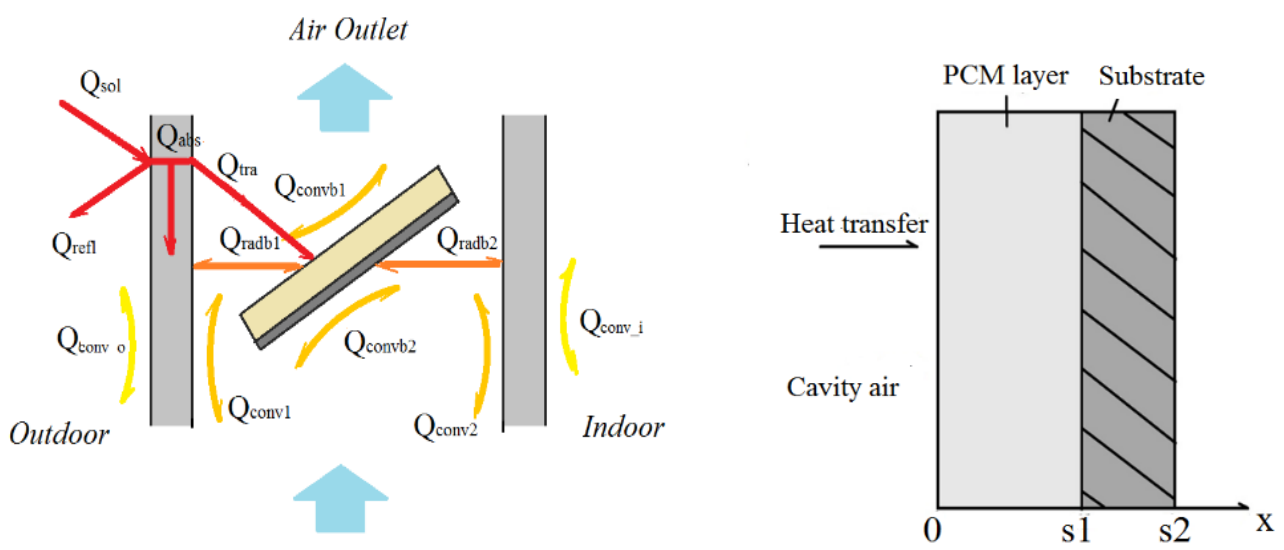

Air Inlet

(a) Integrated DSF system

(b) Sectional view of a PCM blade

Figure 17: Heat transfer paths in the integrated system

The short version of the paper was presented at ICAE2018, Aug 22-25, Hong Kong. This paper is a substantial extension of the short version of the conference paper. 
As shown in Fig.17a, the total solar irradiance $\left(\mathrm{Q}_{\text {sol }}\right)$ reaching the outer skin of DSF can be divided into reflected solar irradiance $\left(\mathrm{Q}_{\mathrm{refl}}\right)$, absorbed solar irradiance $\left(\mathrm{Q}_{\mathrm{abs}}\right)$ and transmitted solar irradiance $\left(\mathrm{Q}_{\text {tra }}\right)$.

$$
Q_{\text {sol }}=Q_{a b s}+Q_{\text {tra }}+Q_{\text {reft }}
$$

The net solar heat gain $\left(\mathrm{Q}_{\text {net }}\right)$ into the DSF system equals to that of the total solar irradiance $\left(\mathrm{Q}_{\text {sol }}\right)$ minus the reflected solar irradiance $\left(\mathrm{Q}_{\text {refl }}\right)$ and the heat loss through convection on the glass skins $\left(\mathrm{Q}_{\text {conv_o }_{-},} \mathrm{Q}_{\text {conv }_{-}}\right)$, and thus can be expressed as:

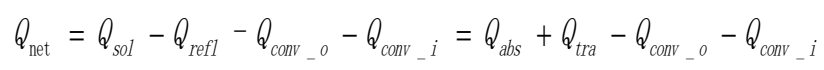

As shown in Fig. 17b, only one-dimensional conduction is considered within the PCM layer. Therefore the heat transfer of the PCM layer $\left(\mathrm{Q}_{\mathrm{b}}\right)$ can be expressed as:

$$
Q_{b}=Q_{t r a}+Q_{r_{d_{-}} b 1}+Q_{c o n v_{-} b 1}=\left.k_{p} \frac{d T_{p}}{d x}\right|_{0<x<s 1}
$$

The energy equation of the PCM layer can be written as:

$$
\begin{aligned}
& \left.\frac{\partial}{\partial t}\right|_{t>0}\left(\rho_{p} H\right)=\left.k_{p} \frac{\partial^{2} T_{p}}{\partial X^{2}}\right|_{0<x<s 1} \\
& H=h+\Delta H \\
& h=h_{r e f}+\int_{T_{r e f}}^{T} c_{P p} d T
\end{aligned}
$$

where $\mathrm{H}$ is the specific enthalpy of PCM, $\mathrm{h}$ is the sensible heat, $\Delta \mathrm{H}$ is the latent heat. The heat conducted from the PCM layer to the substrate on the interface s1 can be expressed as:

$$
\left.k_{p} \frac{d T_{p}}{d x}\right|_{x=s 1}=\left.k_{s} \frac{d T_{s}}{d x}\right|_{x=s 1}
$$

The energy equation within the substrate can be calculated as:

$$
\left.\frac{\partial T_{s}}{\partial t}\right|_{t>0} \rho_{s} c_{P_{s}}=\left.k_{s} \frac{\partial^{2} T_{s}}{\partial x^{2}}\right|_{s 1<x, s 2}
$$


The heat transferred to interface $\mathrm{s} 2$ of the substrate $\left(\mathrm{Q}_{\mathrm{s}}\right)$ can be expressed as follows:

$$
\begin{aligned}
& Q_{s}=\left.k_{s} \frac{d T_{s}}{d x}\right|_{x=s 2} \\
& Q_{s}=Q_{\text {rad_b2 }}+Q_{\text {conv_b } 2}
\end{aligned}
$$

The total heat transfer from the cavity air $\left(\mathrm{Q}_{\mathrm{a}}\right)$ can therefore be calculated as:

$$
\begin{aligned}
& Q_{a}=C_{P a} m_{a} \Delta T_{a} \\
& Q_{a}=Q_{\text {conv_1 }}+Q_{\text {conv_ } 2}+Q_{c o n v_{-} b 1}+Q_{\text {conv } b 2}
\end{aligned}
$$

ANSYS Workbench FLUENT software was used for simulation with RNG k- $\varepsilon$ model as the turbulence model. Navier-Stokes equations were employed for the fluid field in the DSF cavity while the buoyancy effect was simulated by the Boussinesq assumption. The general governing equations of the fluid domain and the air density were expressed as:

$$
\begin{aligned}
& \frac{\partial(\rho \phi)}{\partial t}+\nabla(\rho \vec{U} \phi)=\nabla\left(\Gamma_{\phi} g r a \phi\right)+S_{\phi} \\
& \rho=\rho_{0}(1-\alpha \Delta T)
\end{aligned}
$$

The discrete ordinates (DO) model was adopted as the radiation model and the radiative transfer equation was expressed as:

$$
\frac{d I(\vec{r}, \vec{s})}{d s}+\left(a+\sigma_{s}\right) I(\vec{r}, \vec{s})=a n^{2} \frac{\sigma T^{4}}{\pi}+\frac{\sigma_{s}}{4 \pi} \int_{0}^{4 \pi} I(\vec{r}, \vec{s}) \phi(\vec{r}, \vec{s}) d \Omega
$$

The SIMPLE scheme was selected as the pressure-velocity coupling method while second order approximations were used as solutions of differential equations. The time step for the simulation was 10 s for 8640 steps covering a working cycle of the PCM blind system. The dynamic boundary condition was defined by using the fitted polynomial functions of time-dependent ambient temperature and solar radiation on the monitored hottest day 2014/7/12 [40]. Based on the collected weather and DSF measurements, Tab. 7 provides the DSF data and the additional air properties adopted for the simulation. 
Table 7 DSF data and air properties

\begin{tabular}{lll}
\hline Item & Value & Unit \\
\hline$D S F$ & & \\
External skin & 38.1 & ${ }^{\circ} \mathrm{C}$ \\
temperature & 36.0 & ${ }^{\circ} \mathrm{C}$ \\
Internal skin temperature & 36.0 & ${ }^{\circ} \mathrm{C}$ \\
Cavity air temperature & 36.4 & $\mathrm{~m} / \mathrm{s}$ \\
Inlet air velocity & 0.45 & \\
\hline Air properties & & \\
Thermal conductivity & 0.02 & $\mathrm{~W} / \mathrm{m} \cdot \mathrm{K}$ \\
Kinematic viscosity $(v)$ & 15.11 & $\mathrm{~mm} / \mathrm{s}$ \\
Density $(\rho)$ & 1.20 & $\mathrm{~kg} / \mathrm{m}^{3}$ \\
Thermal diffusivity $(\alpha)$ & 22.5 & $\mathrm{~mm} / \mathrm{s}$ \\
Specific heat $\left(c_{\mathrm{p}}\right)$ & 1.00 & $\mathrm{~kJ} / \mathrm{kg} \cdot \mathrm{K}$ \\
Prandtl number $\left(\operatorname{Pr}_{\mathrm{t}}\right)$ & 0.71 & \\
\hline
\end{tabular}

Previous researchers have studied the influence of blind tilt angle and position of aluminium blind on the DSF thermal performance [10,44]. In this study we simulated and compared the thermal performance of the PCM blind system with different blind tilt angles and positions (in relation to the width of the cavity) in DSF against a conventional aluminium blind case. Tab. 8 lists the six simulation cases (Case0-Case5) covering three blind tilt angles $\left(30^{\circ}, 45^{\circ}, 60^{\circ}\right)$, and three different positions in DSF cavity (Middle, Close to external glass, Close to internal glass). When comparing the PCM blind performance with different blind tilt angles, the blind position is in the middle of DSF cavity. When comparing the system performance with different blind positions, the blind tilt angle is $30^{\circ}$ which corresponded to the local latitude. Case 0 is the reference case of conventional aluminium blind with blind tilt angle of $30^{\circ}$ and position in the middle of DSF cavity.

Table 8 Simulation cases

\begin{tabular}{lllll}
\hline Parameters for comparison & Angle $\left({ }^{\circ}\right)$ & Position & Material & Case \\
\hline PCM blind angle & 30 & Middle & PCM & Case 1 \\
(blind position remains in & 45 & Middle & PCM & Case 2 \\
middle of DSF cavity) & 60 & Middle & PCM & Case 3 \\
& 30 & Middle & PCM & Case 1 \\
PCM blind position & 30 & Close to external glass & PCM & Case 4 \\
(blind tilt angle remains $\left.30^{\circ}\right)$ & 30 & Close to internal glass & PCM & Case 5 \\
Reference case & 30 & Middle & Aluminium & Case 0 \\
\hline
\end{tabular}


In order to validate the numerical models, the simulated and measured average cavity air temperature of the measured position was compared for Case 1 (blind tilt angle: $30^{\circ}$, position: in the middle of DSF cavity, material: PCM) on 2014/7/12. As shown in Fig. 18 , the predicted average air temperature in DSF cavity agreed reasonably well with the measured data as most of the percentage errors between simulated and measured data were lower than $4 \%$.

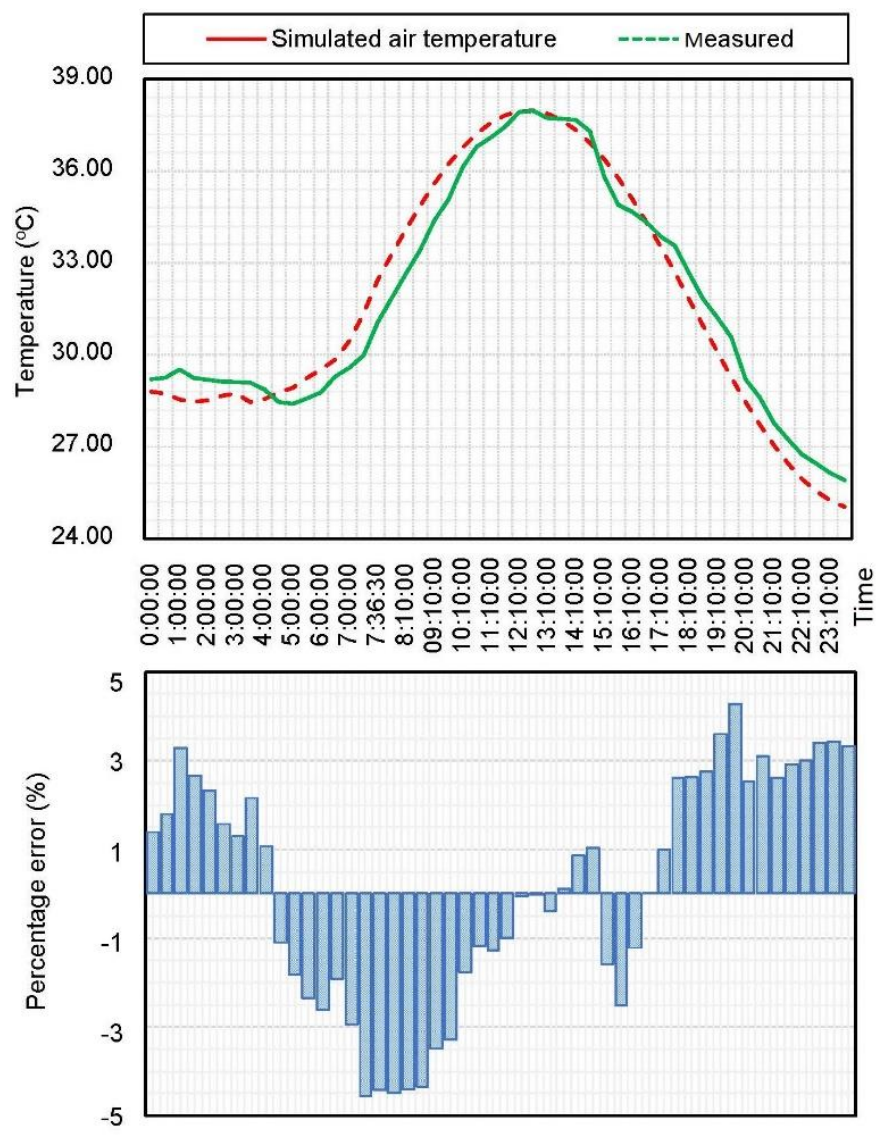

Figure 18: Comparison and errors between simulated and measured DSF air temperatures, 2014/7/12

\subsection{Simulation results}

By using the validated numerical models, the profiles of average cavity air temperature along the height of DSF for different simulation cases were simulated and compared in Fig. 19. It can be seen that the average cavity air temperature along the height of the DSF system integrated with PCM blind (Case1-Case5) was obviously lower than that of the DSF with aluminium blind (Case0). The largest temperature difference between the only-aluminium blind case and the PCM blind was $2.2^{\circ} \mathrm{C}$ and occurred at around The short version of the paper was presented at ICAE2018, Aug 22-25, Hong Kong. This paper is a substantial extension of the short version of the conference paper. 
11:40 am for Case1. This indicates that the PCM blind was able to reduce the cavity air temperature in DSF during the daytime as compared with the aluminium blind.

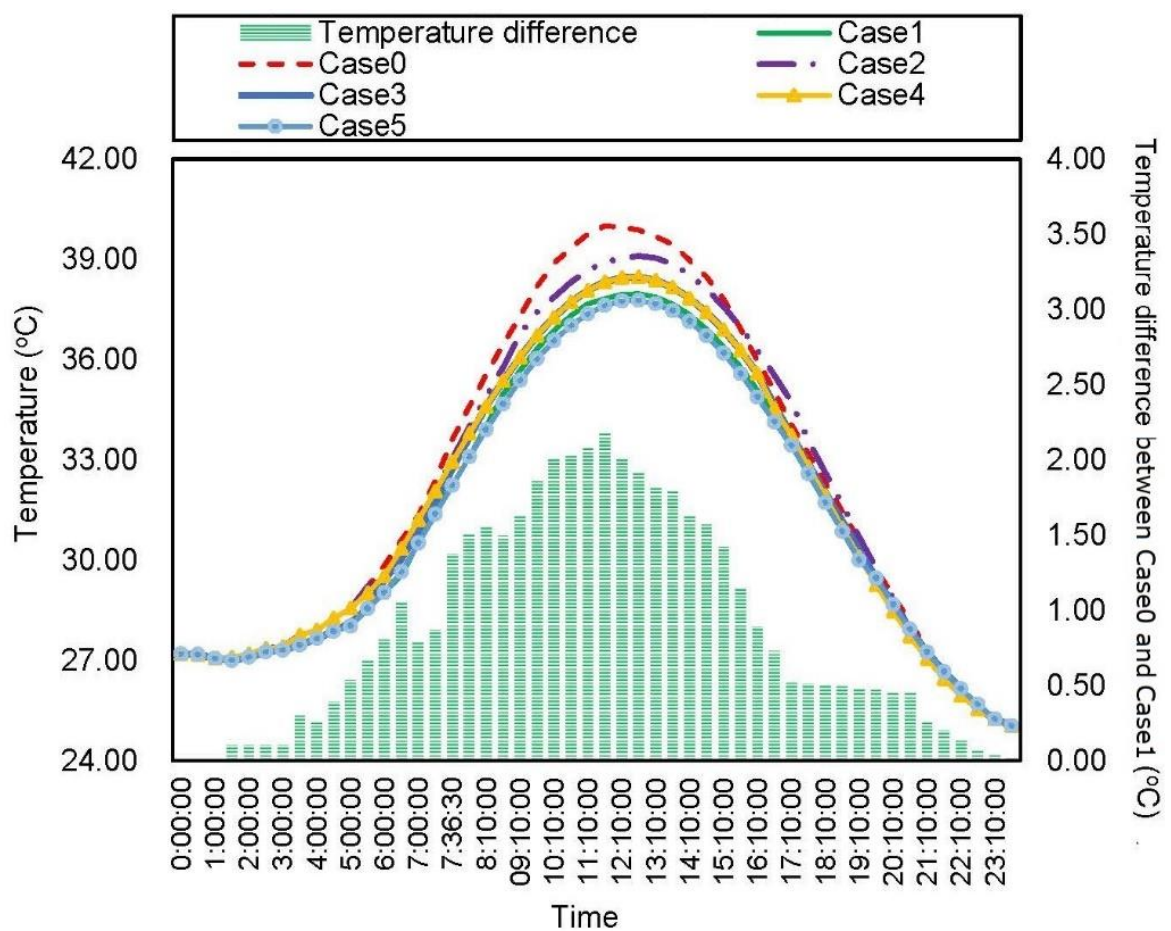

Figure 19: Profiles of average cavity air temperature along the height of DSF for different simulation cases (Case0: aluminium, $30^{\circ}$, middle; Case1: PCM, $30^{\circ}$, middle;

Case2: PCM, $45^{\circ}$, middle; Case3: PCM, $60^{\circ}$, middle; Case4: PCM, $30^{\circ}$, close to external glass; Case 5: PCM, $30^{\circ}$, close to internal glass), and temperature difference between Case 0 and Case 1

Fig. 20 depicts the PCM layer surface temperature profiles with different blind tilt angles. It can be seen that all the temperature profiles follow similar trends, whereas the surface temperature of aluminium blind in Case 0 was obviously higher than those of PCM blinds in other cases. The system in Case 1 (DSF with blind tilt angle of $30^{\circ}$ ) shows the lowest peak temperature. This is mainly due to that the blind tilt angle of $30^{\circ}$ matches better the local latitude which enables the PCM blind to receive a greater amount of solar radiation flux than the other cases. The surface temperature of the system in Case 2 was higher than that in Case 3 because of the higher amount of incidence solar radiation in Case 2 and possibly because the tilt angle of blind system in Case 3 results in slightly larger vertical airflow velocity (daily average outlet vertical 
airflow velocity for Case 2 was $0.50 \mathrm{~m} / \mathrm{s}$ while for Case 3 was $0.52 \mathrm{~m} / \mathrm{s}$ ) in the cavity and therefore slightly higher convective heat transfer on the surface.

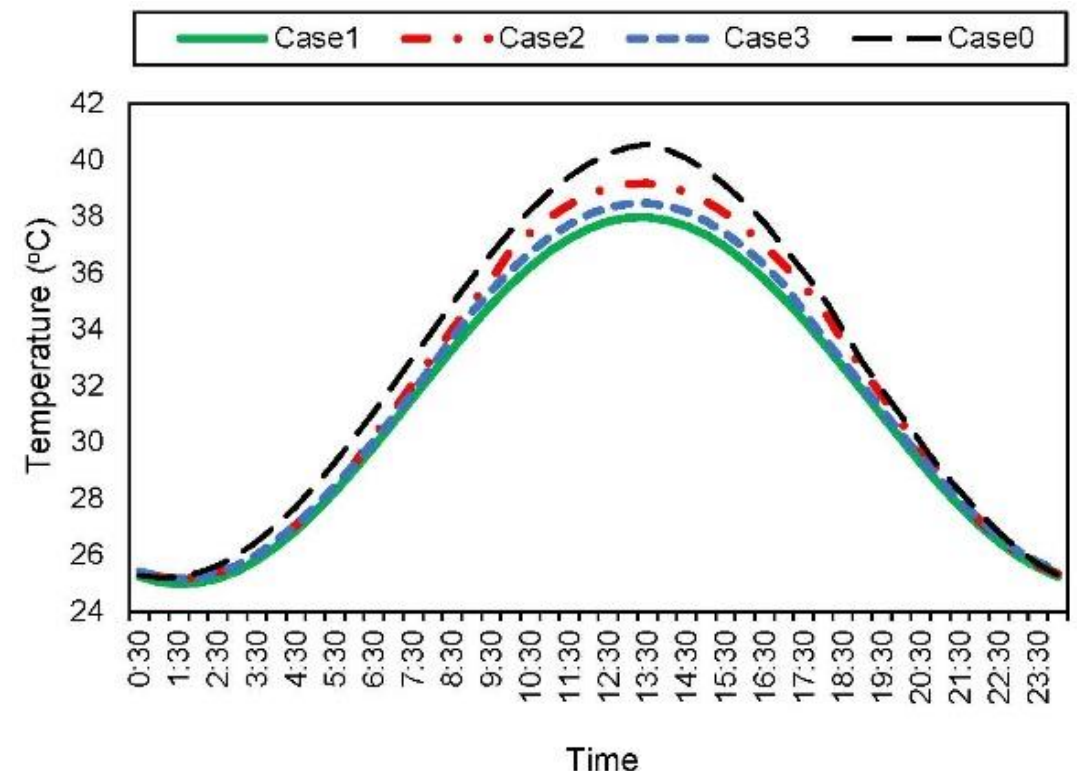

Figure 20: PCM layer surface temperature profiles of integrated DSF-PCM blind system with different blind tilt angle (Case0: $30^{\circ}$, aluminium; Case1: $30^{\circ}, \mathrm{PCM}$;

Case2: $45^{\circ}, \mathrm{PCM}$; Case 3: $\left.60^{\circ}, \mathrm{PCM}\right)$

Fig. 21 demonstrates the PCM layer surface temperature profiles with different blind positions in the DSF. The aluminium blind shows the highest surface temperature compared with the PCM blind cases. All the other temperature profiles follow similar trends. The temperature profile for Case 4 (blind close to external glass skin) was above the others and the temperature profile of Case 5 (blind close to internal glass skin) was the lowest. This was mainly due to the higher glass skin temperature of the external glass skin compared with the internal glass skin. In Case 4, the higher surface air temperature and thinner surface air layer between the external glass skin and the PCM blind influenced the convective heat transfer on the surface of the integrated blind system. 


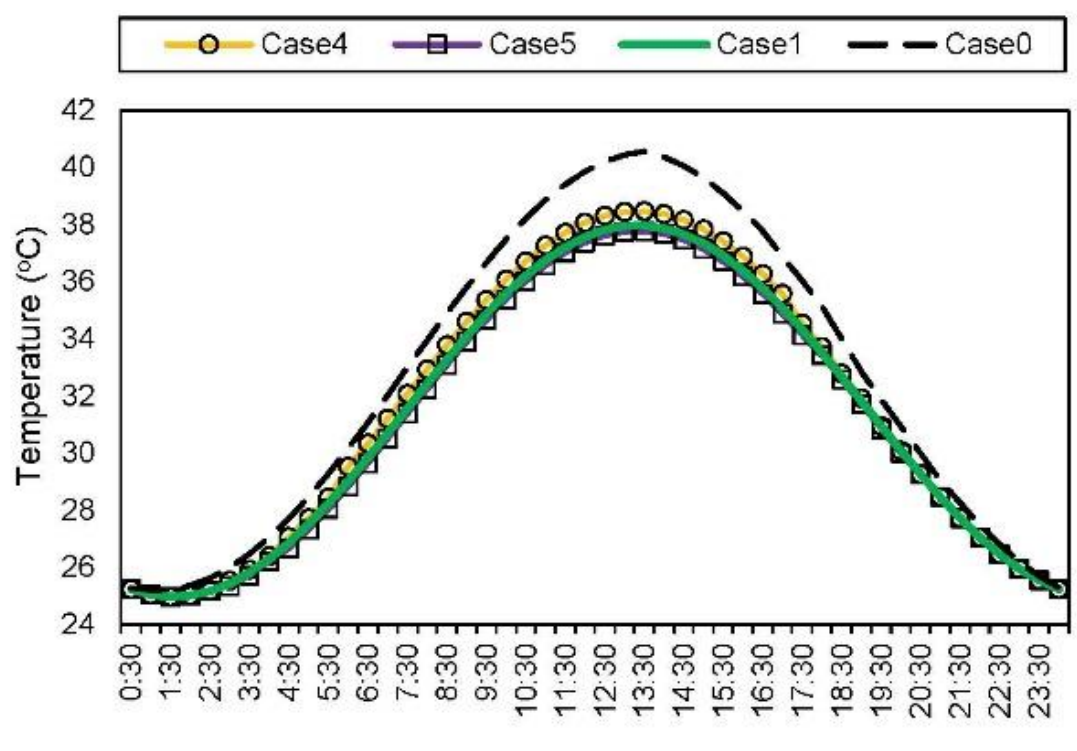

Time

Figure 21: PCM layer surface temperature profiles of integrated DSF-PCM blind system with different blind positions (Case0: Middle, aluminium; Case1: Middle, PCM; Case4: Close to external glass, PCM; Case5: Close to internal glass, PCM)

\section{Conclusions}

A PCM blind system for DSF integration was developed and its thermal performance in summer was theoretically and experimentally evaluated. The specific conclusions can be summarised as follows:

- The air temperature at different positions in DSF test cell did not exceed $39^{\circ} \mathrm{C}$ during the day time and was below its melting point before 10:00 am and after 3:00 pm, which enabled the developed PCM blind system in DSF cavity undergo solidification process even on the hottest days in the summer of the studied area.

- The integrated PCM blind system was able to stabilise the daytime average cavity air temperature to below $35^{\circ} \mathrm{C}$ and showed no significant increase as compared with the ambient temperature.

- With the presence of PCM blind, the surface temperature of the internal glass skin was about $1.0-2.9^{\circ} \mathrm{C}$ lower than the surface temperature of external glass skin during the daytime. The air temperature near the external glass skin of DSF was obviously higher than that near the internal glass skin. 
- The ambient air temperature was the major influencing factor on the system thermal performance during the daytime, and had the most significant impact on the magnitude of temperature of all the layers in DSF throughout the day.

- Simulation results revealed that compared with the traditional aluminium blind, the PCM blind showed larger capacity of reducing cavity air temperature in DSF with $2.2^{\circ} \mathrm{C}$ (about $5.5 \%$ ) decrease in the average cavity air temperature.

- The surface temperature profiles of systems with different blind tilt angles and different blind positions follow similar trends respectively. The PCM layer surface temperature of the blind with blind tilt angle of $30^{\circ}$ was the lowest, possibly because the tilt angle matches better the local latitude. The PCM layer surface temperature of the blind close to the external glass skin integrated DSF was the highest, while that with the blind close to the internal glass skin was the lowest.

Although this study demonstrated great potential of the PCM blind for thermal improvement of DSF, the numerical investigation only compared the performance of PCM blind with a conventional aluminium blind in summer. More comparative studies should be conducted on the PCM blind and other thermal management system for DSFs under varied building scenarios and environmental conditions. Additionally, longerterm experimental campaigns into the energy storage efficiency of the PCM blind due to repeated charging and discharging cycles should be conducted throughout a year in climates with hot daytime periods and high diurnal temperature differences. Lastly, an assessment of the whole life-cycle performance and economic aspects of the PCM blind would also be a worthwhile contribution to knowledge for the potential of applying thermal energy storage materials in buildings.

\section{References}

[1] International Energy Agency. Key World Energy Statistics; 2017.

[2] Leibowicz B D, Lanham C M, Brozynski M T, Vázquez-Canteli J R., Castejón N

C, Nagy Z. Optimal decarbonization pathways for urban residential building energy services. Applied Energy 2018;230:1311-1325.

The short version of the paper was presented at ICAE2018, Aug 22-25, Hong Kong. This paper is a substantial extension of the short version of the conference paper. 
[3] Juaristia M, Gómez-Acebob T, Monge-Barrioa A. Qualitative analysis of promising materials and technologies for the design and evaluation of Climate Adaptive Opaque Façades. Building and Environment 2018;144:482-501.

[4] Wang Y, Chen Y, Zhou J. Dynamic modeling of the ventilated double skin façade in hot summer and cold winter zone in China. Building and Environment 2016;106:365377.

[5] Zhang T, Tan Y, Yang H, Zhang X. The application of air layers in building envelopes: A review. Applied Energy 2016;165:707-734.

[6] Pasquay T. Natural ventilation in high-rise buildings with double facades, saving or waste of energy. Energy and Buildings 2004;36:381-389.

[7] Kim Y M, Lee J H, Kim S M, Kim S. Effects of double skin envelopes on natural ventilation and heating loads in office buildings. Energy and Buildings 2011;43:21182126.

[8] Kim Y M, Kim S Y, Shin S W, Sohn J Y. Contribution of natural ventilation in a double skin envelope to heating load reduction in winter. Building and Environment 2009;44:2236-2244.

[9] Chan A L S, Chow T T, Fong K F, Lin Z. Investigation on energy performance of double skin façade in Hong Kong. Energy and Buildings 2009;41:1135-1142.

[10] Saelens D, Roels S, Hens H. The inlet temperature as a boundary condition for multiple-skin facade modelling. Energy and Buildings 2004;36:825-835.

[11] Tanimoto J, Kimura K. Simulation study on an air flow window system with an integrated roll screen. Energy and Buildings 1997;26:317-325.

[12] Darkwa J, Li Y, Chow D H C. Heat transfer and air movement behaviour in a double-skin façade. Sustainable Cities and Society 2014;10:130-139.

[13] Su Z, Li X, Xue F. Double-skin façade optimization design for different climate zones in China. Solar Energy 2017;155:281-290.

[14] Zeng Z, Li X, Li C, Zhu Y. Modeling ventilation in naturally ventilated doubleskin façade with a venetian blind. Building and Environment 2012;57:1-6. 
[15] Sun Y, Wu Y, Wilson R, Lu S. Experimental measurement and numerical simulation of the thermal performance of a double glazing system with an interstitial Venetian blind. Building and Environment 2016;103:111-122.

[16] Wang Y, Chen Y. Modeling and calculation of solar gains through multi-glazing facades with specular reflection of venetian blind. Solar Energy 2016;130:33-45.

[17] Manz H. Total solar energy transmittance of glass double facades with free convection. Energy and Buildings 2004;36 (2):127-136.

[18] Shen C, Li X. Solar heat gain reduction of double glazing window with cooling pipes embedded in venetian blinds by utilizing natural cooling. Energy and Buildings 2016;112:173-183.

[19] Fallahi A, Haghighat F, Elsadi H. Energy performance assessment of double-skin façade with thermal mass. Energy and Buildings 2010;42:1499-1509.

[20] Sun Y, Liang R, Wu Y, W Robin, R Peter. Development of a comprehensive method to analyse glazing systems with Parallel Slat Transparent Insulation material (PS-TIM). Applied Energy 2017;205:951-963.

[21] Sun Y, Liang R, Wu Y, W Robin, R Peter. Glazing systems with Parallel Slats Transparent Insulation Material (PS-TIM): Evaluation of building energy and daylight performance. Energy and Buildings 2018;159:213-227.

[22] Peng J, Lu L, Yang H, Ma T. Comparative study of the thermal and power performances of a semi-transparent photovoltaic façade under different ventilation modes. Applied Energy 2015;138:572-583.

[23] Peng J, Lu L, Yang H, Ma T. Comparative study of the thermal and power performances of a semi-transparent photovoltaic façade under different ventilation modes. Applied Energy 2015;138:572-583.

[24] Peng J, Curcija D C, Lu L, Selkowitz S E, Yang H, Zhang W. Numerical investigation of the energy saving potential of a semi-transparent photovoltaic doubleskin facade in a cool-summer Mediterranean climate. Applied Energy 2016;165:345356. 
[25] Luo Y, Zhang L, Wang X, Xie L, Liu Z, Wu J, Zhang Y, He X. A comparative study on thermal performance evaluation of a new double skin façade system integrated with photovoltaic blinds. Applied Energy 2017;199:281-293.

[26] Barzin R, Chen J J, Young B R, Farid M M. Application of PCM energy storage in combination with night ventilation for space cooling. Applied Energy 2015;158:412421.

[27] Takeda S, Nagano K, Mochida T, Shimakura K. Development of a ventilation system utilizing thermal energy storage for granules containing phase change material. Solar Energy 2004;77(3):329-38.

[28] De Gracia A, Navarro L, Castell A, Ruiz-Pardo Á, Alvárez S, Cabeza L F. Experimental study of a ventilated facade with PCM during winter period. Energy and Buildings 2013;58:324-332.

[29] De Gracia A, Navarro L, Castell A, Ruiz-Pardo Á, Álvarez S, Cabeza L F. Thermal analysis of a ventilated facade with PCM for cooling applications. Energy and Buildings 2013;65:508-515.

[30] De Gracia A, Navarro L, Castell A, Cabeza L F. Energy performance of a ventilated double skin facade with PCM under different climates. Energy and Buildings 2015;91:37-42.

[31] Diarce G, Urresti A, García-Romero A, Delgado A, Erkoreka A, Escudero C, et al. Ventilated active façades with PCM. Applied Energy 2013;109:530-537.

[32] Diarce G, Campos-Celador Á, Martin K, Urresti A, García-Romero A, Sala J M. A comparative study of the CFD modeling of a ventilated active façade including phase change materials. Applied Energy 2014;126:307-317.

[33] Cabeza L.F., Castell A., Barreneche C., De Gracia A., Fernández A.I.. Materials used as PCM in thermal energy storage in buildings: A review. Renewable and Sustainable Energy Reviews 2011;15:1675-1695.

[34] Su W, Darkwa J, Kokogiannakis G. Development of microencapsulated phase change material for solar thermal energy storage. Applied Thermal Engineering 2017; 112:1205-1212. 
[35] Su W, Darkwa J, Kokogiannakis G. Nanosilicon dioxide hydrosol as surfactant for preparation of microencapsulated phase change materials for thermal energy storage in buildings. International Journal of Low-Carbon Technologies, 2018:cty032-cty.

[36] Weinlaeder H, Koerner W, Heidenfelder M. Monitoring results of an interior sun protection system with integrated latent heat storage. Energy and Buildings 2011; 43:2468-2475.

[37] Silva T, Vicente R, Amaral C, Figueiredo A. Thermal performance of a window shutter containing PCM: Numerical validation and experimental analysis. Applied Energy 2016;179:64-84.

[38] Li Y, Darkwa J, Kokogiannakis G. Heat transfer analysis of an integrated double skin façade and phase change material blind system. Building and Environment 2017;125:111-121.

[39] Darkwa K, Callaghan P W O, Tetlow D. Phase-change drywalls in a passive-solar building. Applied Energy 2006;83:425-435.

[40] Darkwa J, Zhou T. Enhanced laminated composite phase change material for energy storage. Energy Conversion and Management 2011;52:810-815.

[41] Akeiber H, Nejat P, Majid M Z A, Wahid M A, Jomehzadeh F, Famileh I Z, Calautit J K, Hughes B R, Zaki S A. A review on phase change material (PCM) for sustainable passive cooling in building envelopes. Renewable and Sustainable Energy Reviews 2016;60:1470-1497.

[42] Sari A, Alkan C, Bilgin C. Micro/nano encapsulation of some paraffin eutectic mixtures with poly(methyl methacrylate) shell: preparation, characterization and latent heat thermal energy storage properties. Applied Energy 2014;136:217-27.

[43] Data Sheet PX35, R. T. GmbH, Ed., ed, 2013.

[44] Iyi D, Hasan R, Penlington R, Underwood C. Double skin façade: Modelling technique and influence of venetian blinds on the airflow and heat transfer. Applied Thermal Engineering 2014;71:219-229. 